DOCUMENTO OCASIONAL

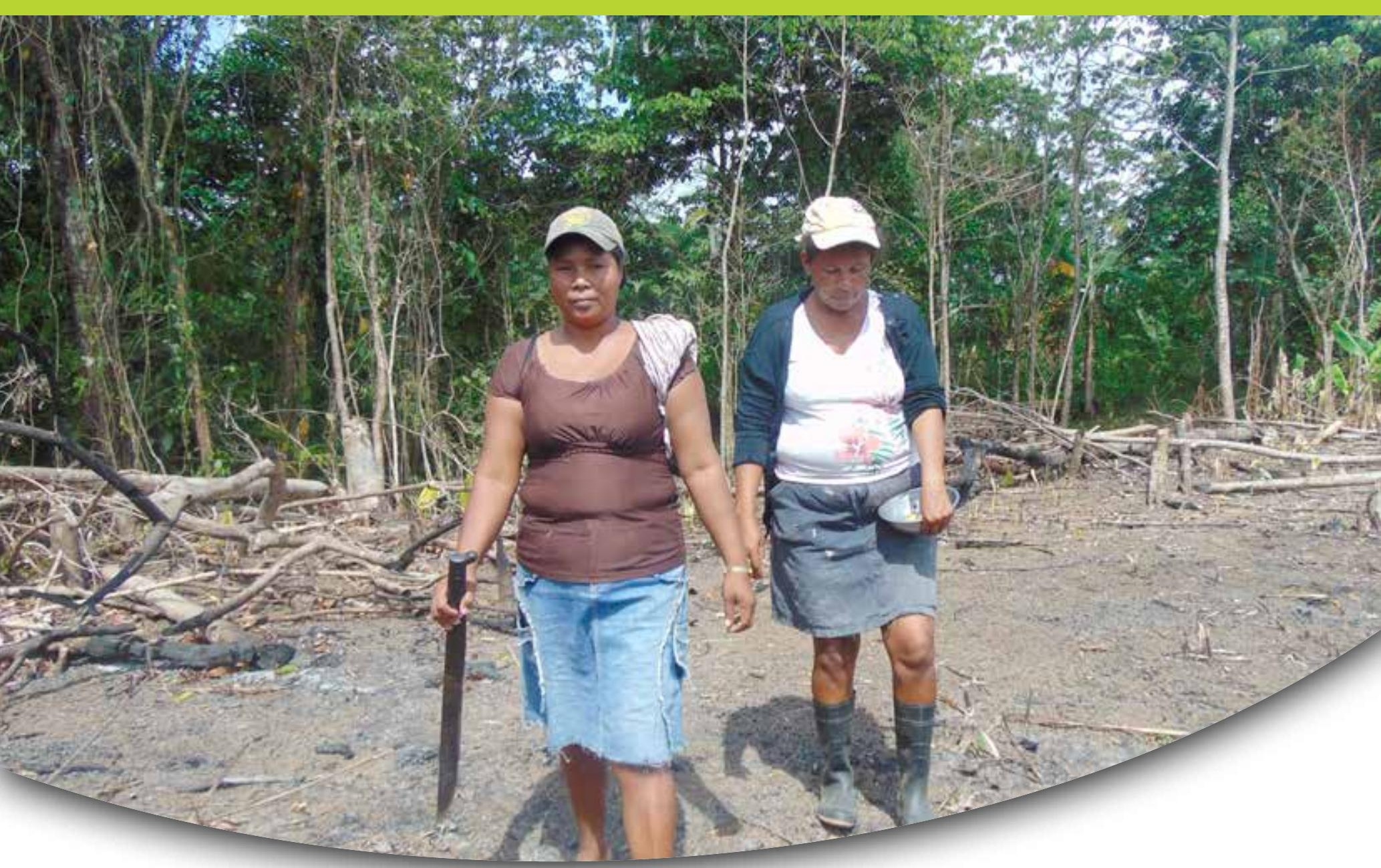

\title{
Una aproximación a las diferencias de género en hogares con bosques privados y bosques comunitarios en Nicaragua
}

Selmira Flores

Anne M. Larson

Kristen Evans
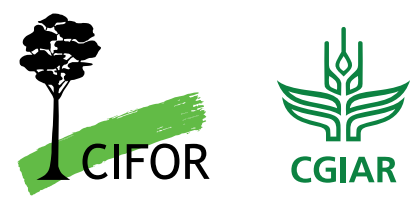

PROGRAMA DE

INVESTIGACIÓN SOBRE

Bosques, Árboles y

Agroforestería

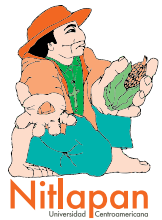




\section{Una aproximación a las diferencias de género en hogares con bosques privados y bosques comunitarios en Nicaragua}

Selmira Flores

Universidad Centroamericana de Managua

Anne M. Larson

CIFOR

Kristen Evans

CIFOR 
Documento Ocasional 161

(C) 2016 Centro para la Investigación Forestal Internacional (CIFOR)

(c) (i) Los contenidos de esta publicación están bajo licencia Creative Commons Attribution 4.0 International (CC BY 4.0), http://creativecommons.org/licenses/by/4.0/

ISBN 978-602-387-040-0

DOI: $10.17528 /$ cifor/006289

Flores S, Larson AM y Evans K. 2016. Una aproximación a las diferencias de género en hogares con bosques privados y bosques comunitarios en Nicaragua. Documento Ocasional 161. Bogor, Indonesia: CIFOR.

Foto por Selmira Flores

\author{
CIFOR \\ Jl. CIFOR, Situ Gede \\ Bogor Barat 16115 \\ Indonesia \\ $\mathrm{T}+62(251) 8622-622$ \\ $F+62(251) 8622-100$ \\ E cifor@cgiar.org
}

\title{
cifor.org
}

Quisiéramos agradecer a todos los donantes que apoyaron esta investigación a través de sus contribuciones al Fondo de CGIAR. Para ver la lista de donantes del Fondo, visite: http://www.cgiar.org/about-us/our-funders/

Cualquier opinión vertida en este documento es de los autores. No refleja necesariamente las opiniones de CIFOR, de las instituciones para las que los autores trabajan o de los financiadores. 


\section{Contenido}

$\begin{array}{ll}\text { Agradecimientos } & \mathbf{v}\end{array}$

Resumen ejecutivo vi vi

1 Introducción 1

2 Rezago, pérdida de bosques e invisibilidad de la mujer: elementos del contexto 3

2.1 Sector forestal rezagado y reducción de la masa boscosa 3

2.2 Participación e invisibilidad de las mujeres en el sector forestal 4

3 Método y características de la muestra $\quad 7$

3.1 El levantamiento de la encuesta y el procesamiento de datos 7

4 Resultados de la encuesta de hogares vinculados al bosque 9

4.1 Percepción sobre la condición de pobreza en los hogares 9

$\begin{array}{ll}4.2 & \text { Actividades económicas de los hogares } \\ \end{array}$

4.3 Tenencia de la tierra y costumbres sobre la herencia en los hogares 12

$\begin{array}{ll}\text { 4.4 Las diferencias de género en el aprovechamiento del bosque } & 13\end{array}$

4.5 Percepción sobre el estado de los productos del bosque 18

4.6 Los hogares en el manejo de los bosques 20

$\begin{array}{lll}4.7 & \text { Resumen } & 24\end{array}$

5 Discusión $\quad 26$

6 Conclusiones

7 Referencias

Anexos $\quad \mathbf{3 4}$

1. Superficie de bosque por comunidad, municipio y departamento 34

2. Listado de encuestas realizadas por sexo en municipios y comunidades 35

3. Pruebas estadísticas de diferencia significativa entre varones y mujeres sobre la relevancia de la actividad de pesca y remesas $\quad 36$

4. Prueba estadística de la significancia de la agricultura de subsistencia por condición del hogar 36

5. Diferencia significativa de la producción forestal según la condición del hogar 36

6. Diferencia significativa de la actividad asalariado temporal según la condición
del hogar

7. Diferencia significativa de la actividad del comercio según la condición
del hogar

8. Diferencia significativa de las remesas según la condición del hogar 37 


\section{Lista de mapas y tablas}

\section{Mapa}

1. Imagen de la cobertura de bosques en el año 1983 y 2011 en Nicaragua 3

\section{Tablas}

1. N.o de encuestados según el parentesco por sexo 8

2. Valoración de la condición de pobreza en los hogares encuestados 9

3. Observación sobre las condiciones físicas de la vivienda de las personas encuestadas $\quad 10$

4. Grado de importancia atribuida a las principales actividades en el hogar 11

5. Promedio de tierra en el hogar según condición de pobreza 12

6. ¿Quiénes heredan los derechos de herencia a la tierra en la familia? (Múltiples respuestas posibles)

7. Mujeres y hombres en la extracción de productos del bosque 14

8. Productos del bosque, quién vende y quién decide cómo utilizar el dinero en los cuatros departamentos

9. Productos del bosque, quién es responsable de las ventas y del control del dinero de la venta en comunidades indígenas

10. Percepción sobre el beneficio de la venta de los productos forestales

11. Opiniones sobre acciones para mejorar las condiciones de los bosques en las comunidades indígenas

12. Contribución y toma de decisiones sobre los bosques

13. Acciones que realizan los esposos por tipo de hogar en condición de pobreza 21

14. Acciones que realizan las esposas por tipo de hogar en condición de pobreza 21

15. Percepción sobre la participación de las mujeres en decisiones sobre los árboles o el bosque (no-indígena)

16. Percepción sobre la participación de las mujeres en decisiones sobre los árboles o el bosque (indígena)

17. Opiniones sobre la calidad de la participación de las mujeres 23

18. Opinión sobre la calidad de la participación de los varones 23 


\section{Agradecimientos}

Nuestro agradecimiento a la Agencia de Cooperación al Desarrollo de Austria (ADA) por su contribución para la realización de este estudio y por permitirnos las reflexiones sobre el tema género y bosques que esperamos contribuyan a la discusión conceptual y las políticas de apoyo al desarrollo.

Agradecemos especialmente a las mujeres y hombres que aceptaron ser encuestadas y encuestados tanto en las comunidades indígenas de la Región Autónoma de la Costa Caribe Norte, donde los bosques son comunitarios, como también a quienes fueron consultadas y consultados en los municipios que se visitaron en los departamentos de Nueva Segovia, Matagalpa, Jinotega y Río San Juan, donde los bosques son privados; sin su tiempo y sus opiniones, la elaboración de este documento no habría sido posible.

Otras colaboradoras en este proceso de la investigación fueron las personas que contribuyeron a la recopilación de la información de campo, en especial, Carmen Collado, Lisania Padilla y Karen Mendoza por la supervisión de campo. Finalmente, nuestro agradecimiento a las revisoras del contenido de esta publicación, Fernanda Soto de la UCA Managua y Nanneke Winter del IOB de la Universidad de Amberes-Bélgica. 


\section{Resumen ejecutivo}

A menudo se dice que muchos grupos que dependen de los bosques son actores marginados y, en muchos casos, que las mujeres son las "administradoras invisibles" de los productos del bosque (FAO, 2013). Sin embargo, hay muchas generalizaciones sobre el tema de género y el uso de los bosques y los recursos forestales. La falta de entendimiento del papel de las mujeres en sus diferentes y diversos contextos lleva no solo a generalizar, sino también a la aprobación de políticas y acciones que no son las más adecuadas. En Nicaragua, las políticas y proyectos de manejo sostenible de los bosques suelen dejar por fuera a las mujeres como un actor con conocimiento, preocupaciones e intereses en el tema (Mairena, et al., 2012).

Para estudiar el rol de mujeres en las actividades y su participación en la toma de decisiones sobre el bosque, implementamos dos encuestas. La primera se realizó en el año 2011, en 300 hogares de 10 comunidades indígenas en la Región Autónoma del Caribe Norte. La segunda, en el año 2014, con 1188 personas en 594 hogares de 23 comunidades dentro de nueve municipios en cuatro departamentos en el oeste y región central del país (Nueva Segovia, Matagalpa, Jinotega y Río San Juan).

Mientras que la primera encuesta se hizo en hogares con disponibilidad de áreas extensas de bosques comunitarios, la segunda abarcó hogares con fragmentos de bosque en tierra privada y usada en actividades agropecuarias, que reflejan el cambio histórico de la vocación del suelo en el país. El tamaño del área de bosque por comunidad en la segunda encuesta osciló entre 39 y 1897 manzanas. El 85\% de esos hogares tienen un área de tierra igual o inferior a las 30 manzanas (21 hectáreas), y el restante 15\%, un área mayor a las 30 manzanas. En la encuesta en los cuatro departamentos y región central, el $49 \%$ de los participantes fueron varones, y el $51 \%$ mujeres, mientras que en la encuesta en las comunidades indígenas, el $47 \%$ fueron varones y el $53 \%$ mujeres.
Las encuestas tenían el objetivo de entender, de manera diferenciada por sexo, el uso de los bosques y los productos forestales y las diferentes percepciones sobre los bosques, la toma de decisiones y la participación en las actividades y organizaciones forestales. También tenía el propósito de analizar algunas diferencias por nivel de pobreza en las familias. La comparación de resultados de las dos encuestas nos permite hacer comparaciones entre comunidades indígenas y no indígenas. Las encuestas sugieren que los recursos forestales son muy importantes para los hogares estudiados, en particular, la leña. Los hombres son los que recolectan la gran mayoría de los productos, y si los venden, son principalmente ellos quienes lo hacen. Sin embargo, hay diferencias importantes a considerar entre las poblaciones indígenas y no indígenas que demuestran la importancia de entender las realidades específicas y evitar generalizaciones. Algunos estudios señalan diferencias importantes por regiones del mundo (Asia, África, América Latina), pero también por país. Algunos hallazgos sobre estas diferencias incluyen:

- Los sesgos de género hacen que los hombres subestimen el trabajo de las mujeres relacionado con los bosques. También hacen que sobrevaloren los beneficios y roles de varones en la toma de decisiones.

- En Nicaragua, los recursos forestales, particularmente la leña, son importantes para la gran mayoría de los hogares rurales estudiados. Muchos hogares indígenas, como también los no indígenas, y particularmente las mujeres, usan y se benefician de una gran variedad de productos del bosque y otros recursos forestales, a diferencia de mujeres de comunidades no indígenas.

- De todos los productos mencionados por las personas encuestadas, son los hombres quienes extraen más productos que las mujeres, con excepción de productos para artesanías en algunos lugares. 
- Las mujeres indígenas se involucran más en la venta de productos forestales que las mujeres no indígenas, $y$, por tanto, las primeras son más proclives a controlar el ingreso por la venta de estos productos.

Pasar de una participación pobre o moderada a una buena participación en la gobernanza de los bosques implicaría apertura para que las mujeres (y también los varones) puedan incrementar su involucramiento en el aprovechamiento de los productos del bosque más allá del autoconsumo en los hogares; en otras palabras, abrir el espacio para un mayor aprovechamiento en función de la generación de ingresos para los hogares tanto en comunidades indígenas como no indígenas, considerando que dicho aprovechamiento difiere del aprovechamiento a gran escala que regula la ley forestal (plantaciones con fines de exportación de madera fina). Esto traería consigo ciertas modificaciones en el marco de la regulación forestal existente, al menos para facilitar en la práctica el uso de los derechos a la producción forestal individual y de pequeńa escala ajustando el marco regulatorio a este nivel (por ejemplo, reconocer la importancia del manejo de la regeneración natural).

No considerar las diferencias de participación y responsabilidades de mujeres y varones en el uso y manejo de los bosques puede terminar, como señalan Manfre \& Rubin (2013), en políticas forestales ineficaces. Queda pendiente examinar cómo internamente en los hogares, las mujeres no solo pueden liberar tiempo de las responsabilidades domésticas para que puedan entrar en procesos de capacitación y formación en temas forestales; a la vez, para ser consideradas con derecho a formar parte de las organizaciones y del involucramiento de estas en actividades que suelen ser tipificadas como masculinas, como el patrullaje en el bosque, la participación en brigadas contra incendios forestales, o aquellas que tienen que ver con el manejo de maquinaria si se tratara de hacer aprovechamiento de ciertos tipos de madera.

Pese a que se identifica un rol femenino en los bosques, existe una falta de reconocimiento hacia dicho rol, tanto por entidades gubernamentales, el sector privado y otras instancias de la sociedad. El reconocimiento de las mujeres debe explicitarse en la política pública (Fraser, 2007); aunque esa política sobre los temas forestales y ambientales presenta retos, no se puede obviar. Ese doble reto es, por un lado, incorporar la equidad de género como principio, y por otro, asegurar su vínculo con otras políticas sectoriales (Ruiz \& Lopez, 2003), de tal manera que ese reconocimiento sea traducido a la acción. Este estudio sugiere que un análisis más profundo dentro de cada región puede también llevarnos a encontrar diferencias relevantes entre las comunidades y culturas indígenas de bosque tropical. 



\section{Introducción}

El sector forestal en Nicaragua sigue rezagado respecto a otros sectores económicos del país pese a haber sido objeto de discusiones, propuestas de políticas y leyes. A la vez, es un sector cuyos principales actores visibles son varones. Poco se conoce de la participación de las mujeres rurales nicaragüenses y de las mujeres indígenas rurales en las discusiones públicas relativas al uso y manejo de los bosques, a pesar que ellas expresan preocupaciones por el daño ambiental.

La preocupación ambiental provocada por la pérdida anual de 70000 hectáreas de bosques hace tres décadas llevó a un marco regulatorio que estableció un conjunto de leyes y normativas que proponen un uso eficiente de recursos y una perspectiva de sostenibilidad económica y ambiental. No obstante, las tensiones sobre el manejo de los bosques siguen siendo relevantes hoy día, particularmente por la expansión de la ganadería extensiva, los cambios en el uso del suelo y la explotación de madera de bosques naturales en vez de bosques cultivados (Bermúdez, et al., 2015) ${ }^{1}$. Las afectaciones recurrentes del cambio climático también confirman la necesidad de prestar mayor importancia al tema forestal.

Las políticas para el manejo sostenible de los bosques y los proyectos forestales suelen dejar por fuera a las mujeres porque las consideran un actor sin conocimiento, preocupaciones e intereses en el tema (Mairena, et al., 2012). Esta situación no es particular de Nicaragua. Como señalan Manfre y Rubin (2013), no solo las iniciativas de desarrollo forestal, sino también los procesos de investigación han obviado a las mujeres y su conocimiento forestal, aunque para ellas el bosque constituye una fuente importante en sus medios

1 El aprovechamiento forestal de plantaciones forestales establecidas para este propósito apenas inicia en el país. de vida y en el bienestar familiar (ver Schmink y Gómez-García, 2015 y Mai, et al., 2011 para obtener un resumen de estudios existentes). En esta investigación, la participación de las mujeres en la toma de decisiones sobre los bosques es un eje central. Partimos de reconocer su interés e involucramiento en el manejo de este recurso, así como su interacción en el hogar y la comunidad, incluyendo el trabajo compartido con los varones.

Este documento presenta los resultados de una encuesta orientada a estudiar el uso de los productos del bosque por parte de los hogares, las percepciones de hombres y mujeres sobre la situación de los recursos, la toma de decisiones y la participación de las mujeres en actividades y organizaciones relacionadas con los bosques. La encuesta está basada en una muestra de las regiones del país, fuera de las regiones autónomas, con mayor disponibilidad de bosques (Norte, Central y Río San Juan), y de las comunidades y de los hogares con acceso a áreas forestales privadas. Una encuesta similar fue levantada en el año 2011 en nueve comunidades indígenas de la Región Autónoma de la Costa Caribe Norte (RACCN), la región forestal más importante del país. Algunos de los datos de la encuesta del 2011 se comparan con los resultados de la desarrollada a inicios del 2015, lo que también nos permite comparar resultados en comunidades indígenas y no indígenas. El propósito principal del estudio ha sido entender la importancia del bosque para los hogares y en particular las diferencias de género existentes en el uso de los recursos forestales, las perspectivas $\mathrm{y}$ las decisiones que se toman en el manejo y aprovechamiento de estos recursos.

Los resultados se presentan en cinco secciones. La primera corresponde a esta introducción. La segunda trata los elementos del contexto en que tiene lugar el estudio, iniciando con los problemas de la pérdida de bosques, el sesgo agrícola sobre la 
tierra con o sin bosques, y la invisibilidad de las mujeres en el sector forestal, un aspecto derivado de las relaciones sociales de género que terminan en diferencias en detrimento del bienestar de las mujeres. La tercera sección presenta la metodología de la encuesta y las características de los hogares en la muestra. La cuarta incluye los resultados de las encuestas, mientras que la quinta sección avanza hacia la discusión sobre los resultados destacando el tema de la participación de las mujeres en un contexto de problemas de manejo de recursos forestales. La sección final plantea las conclusiones. 


\section{Rezago, pérdida de bosques e invisibilidad de la mujer: Elementos del contexto}

\subsection{Sector forestal rezagado y reducción de la masa boscosa}

El sector forestal en Nicaragua se encuentra rezagado en comparación con otros sectores de la economía. Su contribución al Producto Interno Bruto es del 1,3\%, mientras que el sector agropecuario contribuye al 19\% (MAGFOR, 2008). Las actividades agrícolas y pecuarias han crecido de manera periódica a expensas de los bosques, es decir que el crecimiento del sector agropecuario tiene lugar por la incorporación de más áreas de cultivos y no por un incremento de la productividad de las áreas en uso. En otras palabras, la agricultura crece en la medida en que desaparecen los bosques.
De acuerdo con INAFOR (2009), entre 1983 y 2000, 2 millones de hectáreas de bosques desaparecieron modificando la panorámica visual de la superficie del país, situación agravada en los años recientes, como se puede apreciar en el Mapa 1.

La gravedad de la deforestación animó compromisos públicos y programas de reforestación en un esfuerzo por intentar revertir la pérdida de bosques. Sin embargo, los esfuerzos realizados no han sido tan agresivos y contundentes como lo ha sido la deforestación. Entre los años 1975 y 2000, el establecimiento de plantaciones forestales, ya sean mixtas (es decir, que combinan sistemas agro-forestales o silvopastoriles) o puras,

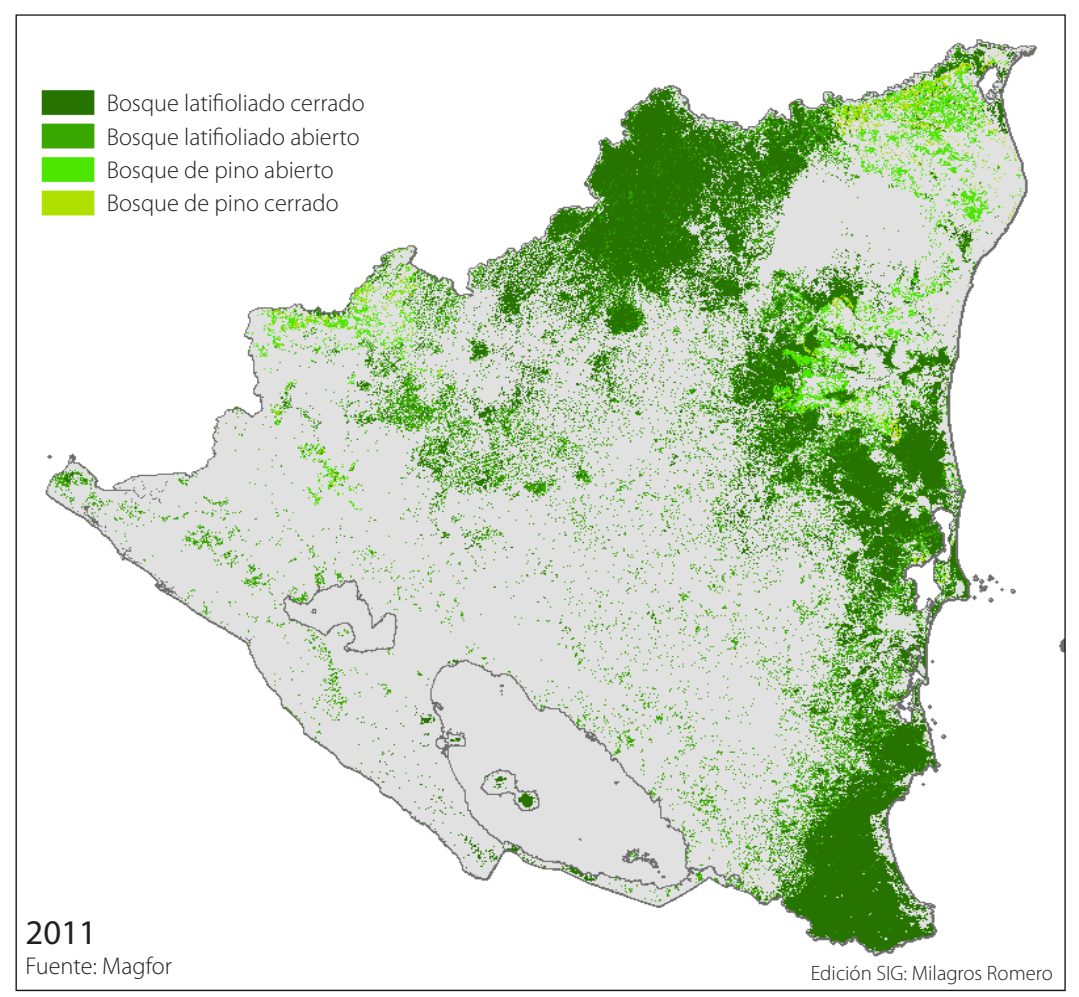

Mapa 1. Imagen de la cobertura de bosques en el año 1983 y 2011 en Nicaragua 
fue en promedio 2237 hectáreas por año, $78 \%$ de las cuales fueron creadas con fondos del sector público a través de proyectos ${ }^{2}$ y un $22 \%$ por inversiones del sector privado (Guevara, 2004). La política para el aprovechamiento forestal estableció la condición de elaborar el Plan de Manejo Forestal, que obliga a plantar árboles por cada árbol extraído. No obstante, como señala Contreras (2011), en la práctica, muchas de las medidas o políticas que han intentado revertir la situación de deforestación no han tenido el efecto deseado, y muchas de esas políticas tienen procesos engorrosos de trámites que resultan en que el problema persista.

Históricamente, el aprovechamiento forestal se ha concentrado en la madera como materia prima y menos en su procesamiento. La industria forestal trabaja en el primer nivel de transformación del árbol. En 2004, Guevara (2004) reportó 76 empresas aserradoras, la mayoría propiedad de varones, que estaban a cargo del primer procesamiento de la madera. La segunda transformación representaba 3033 micro, pequeñas y medianas empresas (mipymes) enfocadas en la producción de muebles para el hogar y oficina, incluyendo puertas y ventanas orientadas a satisfacer la demanda del mercado interno. En 2013, Ortega (2014) señaló que de un total de 109 aserríos, solamente 57 estaban activos y en ese mismo año hubo un registro de 2207 mipymes. Los productos no maderables del bosque $\mathrm{e}^{3} \mathrm{se}$ aprovechan poco, se comercializan internamente y en bajo volumen, por lo que no hay registros que permitan conocer acerca de su contribución económica (Guevara, 2004).

En el año 2010, las exportaciones de madera, carbón vegetal y manufactura de madera fueron de 9197,61 (miles de dólares/precio FOB). En 2014,

2 En 21 proyectos, la inversión de recursos ha sido de unos 125 millones de dólares; el 15\% de los fondos han sido una contribución del gobierno de Nicaragua, y el $85 \%$ han sido fondos provenientes de organismos multilaterales como el Banco Mundial y el Banco Interamericano de Desarrollo (BID), y de agencias de cooperación al desarrollo como la Cooperación Alemana al Desarrollo (GIZ), la Agencia Suiza para el Desarrollo y la Cooperación (COSUDE), Agencia Danesa de Desarrollo Internacional (DANIDA), y Agencia de los Estados Unidos para el Desarrollo Internacional (USAID), entre otros.

3 Por ejemplo: bejucos, mimbre, musgos, resinas, palmas, hojas, cortezas de árboles, cañas silvestres, plantas productoras de fibras, raíces, helechos, látex y gomas. se situaron en los 18762,95 (miles de dólares/ precio $\mathrm{FOB})^{4}$. El último informe del Banco Central de Nicaragua señala que los productos de la madera crecieron en 2014 en un $40,8 \%$ respecto al año 2013 (BCN, 2014, p. 38). Sin embargo, el informe también indica que las actividades silvícolas decrecieron un $0,4 \%$, debido al menor aporte de la extracción de leña, troncos de madera y otros productos de la silvicultura; disminución que atribuyen a una menor demanda de dichos productos.

Entre las oportunidades de inversión para el sector forestal, PRONicaragua, la entidad a cargo de la promoción de la inversión extranjera en el país, anima a invertir en cuatro áreas: plantaciones forestales de madera con valor comercial, plantaciones de hule (caucho), crédito de carbono y producción de cacao para la exportación. ${ }^{5}$ Algunas de las empresas privadas con inversiones en el sector forestal son el Grupo Pellas, AgroForestal S.A y Precious Woods, que han establecido plantaciones forestales, algunos con fines de producción de energía (eucalipto) para obtener madera preciosa como teca, y otras han invertido en el establecimiento de plantaciones de palma o cacao.

\subsection{Participación e invisibilidad de las mujeres en el sector forestal}

Escasos documentos sobre el sector forestal del país abordan el tema de la participación de las mujeres y los hombres en las actividades forestales (Mairena, et al., 2012). Los documentos oficiales que analizan la problemática o el marco legal del sector forestal se centran en la cuestión de la pérdida del área boscosa y la necesidad de regulación. Sin embargo, como señaló Larson (2006), aunque muchos grupos dependen directamente de los recursos forestales, son actores marginados en las leyes o programas nacionales forestales. Se trata de los pequeños dueños de bosques en propiedad privada, las comunidades indígenas con propiedad comunitaria, las mujeres y los campesinos que siembran árboles en sus parcelas y fincas.

\footnotetext{
4 Ver https://www.dga.gob.ni/Estadweb/WEB2014.pdf (ver cuadro pág.6)

5 Ver http://pronicaragua.gob.ni/es/oportunidades-deinversion/194-procesamiento-de-alimentos/
} 
Por otra parte, a medida que las políticas de género se han ido incorporando en el ámbito de las entidades públicas, hay intentos de visibilizar y mejorar la participación y la contribución de mujeres y hombres en el sector forestal (Mairena, et al., 2012). Aunque con problemas de subregistro, en 2009 el empleo femenino directo registrado en el sector forestal era de 431 empleos frente a 1864 empleos masculinos en los distritos forestales donde se recolectó este dato (INAFOR, 2009, p. 69). Por otra parte, el inventario forestal realizado por el Instituto Nacional Forestal entre 2007 y 2008, indagó sobre las actividades socioeconómicas de los miembros de las familias con bosques. Para el $40 \%$ de los varones en los hogares encuestados, la agricultura es la principal actividad, para el $24 \%$ la actividad forestal y para el $22 \%$ la ganadería. En cambio, para el 69\% de las mujeres en esos mismos hogares, la principal actividad es el trabajo doméstico, para el 6,48\% lo es la agricultura y para el 6,38\%, las actividades escolares. Solo el 5,87\% de las mujeres indicó la actividad forestal como su actividad principal, es decir que el porcentaje para las actividades forestales y agrícolas, en el caso de las mujeres, es bastante parecido, pero la relación entre agrícola y forestal difiere considerablemente en el porcentaje de varones. En el caso de los hijos y las hijas en esos hogares, se dedican en primera instancia a "las tareas escolares (ambos casos), a la agricultura (caso de los niños) y al trabajo doméstico (caso de las niñas). La actividad forestal es la actividad de menor involucramiento" para niños y niñas (INAFOR, 2009, p. 119).

En general, la participación de las mujeres queda escondida. El trabajo de GFA Consulting Group (2008) que apoyó el conglomerado forestal en el oeste del país (León y Chinandega) señaló que una de las razones por las cuales no se hace explícita la participación de mujeres en las actividades forestales es causada por la desarticulación del sector, pero a la vez porque ellas lo hacen como parte del esfuerzo colectivo de la familia que involucra a todos sus integrantes, un aspecto que el mercado ignora por su enfoque centrado en el individuo-hombre como actor de la economía. GFA Consulting Group encontró que la participación de las mujeres se da en varias actividades, pero se suele reconocer un rol femenino predominante en el establecimiento y manejo de los viveros. En particular la siembra y el riego son dos tareas asignadas a mujeres dada la percepción común de los cuidados con que ellas realizan estas labores. Las mujeres se involucran en la recolección, producción y selección de semillas. También participan en la siembra de los árboles (incluye el ahoyado) y en su cuidado una vez que se han trasplantado. Sin embargo, la venta de productos forestales, principalmente de la madera, es controlada por los hombres (ibid.). La participación femenina en el aserrado de madera, por ejemplo, solo representa el 1\% (Ortega, 2014).

En general, existe una clara diferenciación y desigualdad de género. Agarwal (1990) señala que, en países como la India, las mujeres también son las más afectadas por los procesos de degradación ambiental y la concentración de recursos, y quienes muestran mayor activismo en los movimientos ecológicos. Alcorn (2014) argumenta que culturalmente, en la sociedad indígena de la Amazonía latinoamericana, las mujeres y los hombres tienden a ser más igualitarios en sus relaciones de género, comparten tareas como la caza de animales y los cultivos para el consumo familiar, y ellas ocupan posiciones de liderazgo; sin embargo, estas normas culturales indígenas se ven gravemente erosionadas cuando se trata de vender productos al mercado dado que el vínculo con el mercado es dominado por los varones. Schmink y García (2015) también coinciden en que las mujeres quedan excluidas del manejo forestal cuando los productos del bosque adquieren valor de mercado, es decir que no solo pueden aprovechar las oportunidades de mercado, también se van quedando sin los recursos que necesitan para vivir en la medida en que se vuelven más escasos.

En América Latina, la FAO (2009) reconoce a las mujeres como "administradoras invisibles y cotidianas" de los recursos naturales. También se reconoce que hombres y mujeres de las áreas rurales adquieren o desarrollan conocimientos distintos sobre los recursos forestales y funcionan diferente en la manera en que se ordenan los bosques y los árboles (FAO, 2013). "Las mujeres suelen establecer sistemas de producción agroforestal tradicionales cercanos a las casas (huertos caseros), recolectan y venden madera y productos derivados de los árboles como parte de estrategias para complementar los ingresos al hogar. Ellas son responsables de la recolección de leña para el hogar y de plantas silvestres utilizadas como alimentos o medicinas" (FAO, 2009, p. 21), aunque Sunderland, et al. (2014) mostraron que hay diferencias de responsabilidades según la región 
del mundo donde habitan, por ejemplo, en África las mujeres son recolectoras de productos del bosque, pero en América del Sur la recolección es una actividad dominada por los hombres, mientras que en Asia las relaciones de género son más equitativas, ya que tanto hombres como mujeres se involucran en las diferentes actividades.

Tener en consideración la manera en que se establecen las diferencias de participación y responsabilidades de mujeres y varones es un aspecto clave, e ignorarlo da lugar a una evaluación negativa de los efectos de las políticas forestales en las personas y las comunidades (Manfre y Rubin, 2013). Esa participación y las maneras distintas en que hombres y mujeres se involucran en las actividades forestales a menudo quedan por fuera cuando se formulan e implementan proyectos forestales ya sea como parte de políticas públicas manejadas por los gobiernos como por aquellos manejados por organizaciones no gubernamentales apoyados con fondos de la cooperación al desarrollo. Schmink y GómezGarcía (2015) afirman que son sobre todo varones los participantes y beneficiarios de los proyectos de manejo forestal, ellos se ponen a cargo a pesar de no tener mucho conocimiento sobre lo que implica el manejo forestal de acuerdo con las regulaciones establecidas.

En resumen, pese a que se identifica claramente un rol femenino en los bosques, existe una falta de reconocimiento de este. El reconocimiento explícito por entidades gubernamentales, sector privado y otras instancias de la sociedad es clave para un acercamiento hacia la equidad de género en el sector forestal. El reconocimiento debe expresarse en la política pública sobre temas forestales y ambientales, que aunque presenta un doble reto - por un lado, incorporar la equidad como principio, y por otro, asegurar su vínculo con otras políticas sectoriales (Ruiz y López, 2003) y ambientales-, no se puede obviar. Como se ha señalado, ignorar la participación de las mujeres y las diferencias de género existentes en el uso y manejo de los bosques puede llevar a políticas públicas poco eficaces (Manfre y Rubin, 2013). 


\section{Método y características de la muestra}

El método del estudio fue una encuesta de hogares (ver anexo 1) con acceso a, o con propiedad de, áreas de bosques en los principales lugares con bosques del país, excluyendo la Región Autónoma del Caribe Norte, donde la encuesta fue levantada en 2011. En cada hogar se encuestaron por separado a una mujer y un hombre, que preferiblemente sean pareja. Las encuestas se llevaron a cabo utilizando el software CSPro y se procesaron en SPSS.

La muestra inicial incluía 19 comunidades y 35 hogares por comunidad en los departamentos Nueva Segovia, Matagalpa, Jinotega y Río San Juan, que de acuerdo al Sistema Nacional Forestal, concentran las mayores áreas de bosques de tres tipos: bosque tropical latifoliado siempre verde en el que también se combinan sistemas agroforestales (en Matagalpa con plantaciones de café), bosque de pinos altamente intervenidos (en Nueva Segovia) y bosque siempre verde intervenido y de áreas protegidas (Río San Juan, Jinotega y una parte de Matagalpa-Peñas Blancas). En la muestra se incluyeron sitios con presencia de organizaciones que aglutinaran a dueños de bosques, algo particular para el caso de Nueva Segovia, en tanto la mayoría de organizaciones de dueños de bosques están ubicados en este departamento, cuyos bosques son coníferos altamente intervenidos.

Las comunidades se seleccionaron de la lista de municipios con mayor número de manzanas de bosque (una manzana equivale a alrededor de 0,7 hectáreas). En cada municipio, la cantidad de bosque por comunidad osciló entre 39 manzanas, la más pequeña, y 1897 manzanas, la de mayor extensión de bosque (ver anexo 1). El 85\% de los hogares con propiedades cuyo tamaño del área es igual o inferior a las 30 manzanas (21 hectáreas) y el restante $15 \%$ son propiedades mayores a las 30 manzanas. En ambos casos se trató de hogares con fragmentos de bosque privado y tierra usada en actividades agropecuarias, que reflejan el cambio histórico de la vocación del suelo en el país, es decir la transformación de extensas áreas de bosque en áreas para fines agropecuarios y la tensión existente entre ambos sectores de la economía. En cada comunidad, con el apoyo de líderes, se elaboró primero una lista de hogares con áreas propias de bosque o con acceso a bosques en la misma comunidad. La lista incluyó dos nombres que correspondían a la pareja (hombre y mujer) y así se levantó el total de hogares que tuvieran bosques en las comunidades seleccionadas. De la lista por comunidad, se seleccionaron los primeros 35 casos de la lista usando la tabla de números aleatorios. A partir del caso número 36 de la lista, se constituyeron los casos de reemplazo para aquellos a sustituir, porque no se encontraron en el momento de la visita.

\subsection{El levantamiento de la encuesta y el procesamiento de datos}

El levantamiento de las encuestas se hizo con ocho encuestadores varones ${ }^{6}$ y dos supervisoras. Se asignaron dos encuestadores por hogar para hacer dos encuestas simultáneas, una con la mujer y otra con el hombre, siempre por separado. En los casos en que se encontraba solo uno de los dos y ningún otro miembro del hogar del sexo opuesto, se optó por hacer la entrevista a la persona que se encontraba en el momento y luego retornar para completar la segunda encuesta con la segunda persona. En general fueron pocos casos dado que por el período en que se realizaron las encuestas, la actividad agrícola o forestal suele

6 Aquí tuvo peso el criterio de saber manejar moto para movilizarse dentro de las comunidades y entre ellas. Durante la capacitación para la realización de la encuesta, se hicieron ejercicios para ayudar a que el grupo de encuestadores sepa cómo manejar el protagonismo que toman los varones en el hogar ante una visita, y así lograr que las mujeres respondieran ellas mismas. 
ser de baja intensidad y la mayor parte de los varones y mujeres se encontraron durante la primera visita. La encuesta fue implementada entre los meses de octubre y noviembre del 2014. Por último, el número de comunidades incluidas en la encuesta subió de 19 (las previstas inicialmente) a 23 debido al escaso número de hogares en algunas comunidades seleccionadas, lo que obligó a complementar con hogares de comunidades cercanas con presencia de familias con áreas de bosque.

Se encuestaron a 1188 personas en 594 hogares de 23 comunidades en nueve municipios en tres departamentos del país (ver anexo 2). Del total de personas encuestadas 583 fueron varones (49\%) y 605 mujeres $(51 \%)$, con diferentes grados de parentesco en el seno de los hogares (ver tabla 1). Como se señaló antes, la encuesta se orientó a las parejas (hombre y mujer) como jefes del hogar o como esposa y esposo, pero se consideró la posibilidad de encuestar a otros miembros del hogar, en caso de ausencia de uno de los esposos. Esta segunda opción se permitía siempre y cuando fuese del sexo opuesto para garantizar balance entre los géneros. También se abrió la posibilidad de entrevistar a dos personas del mismo sexo en casos donde no hubiese personas del sexo opuesto, como en los hogares conformados por madres solteras, y en el que, si bien hay hijos varones, era probable o que estos fuesen menores de edad o no estuvieran el momento de la encuesta.

De los 594 hogares encuestados, en el 94\% (557 hogares) se encuestó a un hombre y una mujer, mientras que en 37 hogares $(6 \%$ del total) se entrevistó a dos personas del mismo sexo (74 encuestas).

La tabla 1 muestra el número de personas por sexo según el parentesco con los varones jefes del hogar. En la tabla también se observan 28 mujeres en la categoría otra, la cual se trató de cuñadas y nueras. En el caso de la categoría otro en varones, el parentesco corresponde a sobrino, primo, cuñado o suegro.
Tabla 1. N.$^{\circ}$ de encuestados según el parentesco por sexo

\begin{tabular}{lrrr}
\hline Parentesco & Varones & Mujeres & Total \\
\hline Esposo & 483 & 0 & 483 \\
\hline Esposa & 0 & 508 & 508 \\
\hline Madre & 0 & 14 & 14 \\
\hline Hijo & 83 & 0 & 83 \\
\hline Hija & 0 & 46 & 46 \\
\hline Nieto & 2 & 0 & 2 \\
\hline Nieta & 0 & 2 & 2 \\
\hline Hermano & 6 & 0 & 6 \\
\hline Hermana & 0 & 7 & 7 \\
\hline Otro & 9 & 0 & 9 \\
\hline Otra & 0 & 28 & 28 \\
\hline Total & 583 & 605 & 1188 \\
\hline
\end{tabular}

Fuente: Encuesta a hogares con acceso a bosques en

Nueva Segovia, Matagalpa, Jinotega y Río San Juan

El instrumento que se utilizó para llevar a cabo la encuesta en la RACCN fue muy similar. Se seleccionaron 9 comunidades para la encuesta de un universo de 18 que representaron una variedad de presiones sobre los bosques. Se entrevistaron un total de 300 personas: 142 hombres y 158 mujeres. En este caso, en vez de hacer una encuesta intrahogar, se alternó entre hombres y mujeres entre los hogares.

El procesamiento de los datos de la encuesta nacional se realizó utilizando el software SPSS, y para aquellos casos donde se notaron diferencias entre las respuestas de hombres y mujeres, se realizó una prueba de significancia estadística auxiliándonos del software STATA. La diferencia estadísticamente significativa se asume cuando el valor de la probabilidad es el menor posible. A menudo se trata de una prueba estadística que determina si hay o no asociación entre las variables que se ponen a prueba, como se mencionará en la sección siguiente, que describe los resultados incluyendo aquellas variables en donde se notaron diferencias entre hombres y mujeres. 


\section{Resultados de la encuesta de hogares vinculados al bosque}

A continuación, se presentan los resultados de la encuesta nacional a los hogares comparados con los resultados de la encuesta realizada en comunidades indígenas en las preguntas que podían compararse. La presentación de resultados se enfoca en las diferencias entre hombres y mujeres y las diferencias entre territorios indígenas y el resto del país. Iniciamos con las características de los hogares de la encuesta levantada en los cuatro departamentos, las cuales están basadas en la autopercepción de las personas encuestadas respecto a su situación de pobreza.

\subsection{Percepción sobre la condición de pobreza en los hogares}

La pregunta sobre la percepción de pobreza de los hogares estuvo orientada a conocer cómo se autodefinen los hogares. La percepción de sí mismos resulta relevante para el análisis comparativo de las respuestas de mujeres y varones, permite identificar si hay alguna relación entre la manera en que perciben su condición, los roles de género y el uso del bosque. La pregunta, ¿cómo define la condición de su familia en relación a otras familias de la comunidad? tenía tres opciones de respuesta: pobre, muy pobre, y no pobre. $\mathrm{El} 70 \%$ señaló a sus hogares como pobres, el $22,73 \%$ se catalogó como no pobres, y el 7,17\% como muy pobres. Este porcentaje difiere ligeramente del que se presenta en la tabla 2 porque no incluye a los que no opinaron (31 hogares). Aunque mujeres y varones coinciden en la forma en que se distribuyen sus respuestas entre los tres tipos de hogares, ellas tienen un porcentaje algo superior a los varones en los hogares muy pobres y pobres y más bajo en los hogares no pobres, indicando que se ubican entre los estratos más pobres y pobres.

Las respuestas de quienes clasificaron la condición de su hogar como muy pobre estuvieron
Tabla 2. Valoración de la condición de pobreza en los hogares encuestados

\begin{tabular}{|c|c|c|c|c|c|c|}
\hline \multicolumn{2}{|c|}{$\begin{array}{l}\text { Criterio de } \\
\text { comparación }\end{array}$} & \multicolumn{4}{|c|}{$\begin{array}{l}\text { Autopercepción de la } \\
\text { condición del hogar }\end{array}$} & \multirow[t]{2}{*}{ Total } \\
\hline & & $\begin{array}{c}\text { No } \\
\text { opinó }\end{array}$ & $\begin{array}{l}\text { Muy } \\
\text { pobre }\end{array}$ & Pobre & $\begin{array}{c}\text { No } \\
\text { pobre }\end{array}$ & \\
\hline \multirow[t]{2}{*}{ VARONES } & $\mathrm{N}$ & 15 & 38 & 394 & 136 & 583 \\
\hline & $\%$ & 2,6 & 6,5 & 67,6 & 23,3 & 100 \\
\hline \multirow[t]{2}{*}{ MUJERES } & $\mathrm{N}$ & 16 & 45 & 417 & 127 & 605 \\
\hline & $\%$ & 2,6 & 7,4 & 68,9 & 21,0 & 100 \\
\hline \multirow[t]{2}{*}{ TOTAL } & $\mathrm{N}$ & 31 & 83 & 811 & 263 & 1188 \\
\hline & $\%$ & 2,6 & 7,0 & 68,3 & 22,1 & 100 \\
\hline
\end{tabular}

Fuente: Encuesta a hogares con acceso a bosques en Nueva Segovia, Matagalpa, Jinotega y Río San Juan

relacionadas con no contar con ingresos estables y a menudo enfrentar dificultades para asegurar los alimentos y otras necesidades de la familia. En cambio, quienes clasificaron a su hogar como pobre lo explicaron por el hecho de tener que trabajar para otros, tener pocos recursos productivos (tierra, bajos rendimientos productivos, poco dinero), no disponer de suficientes alimentos para comercializar y tener trabajo e ingresos temporales. Por otro lado, los que se definieron como hogares no pobres, se perciben en una mejor situación que el resto en cuanto a recursos productivos, vivir más cómodos y no tener problemas de abastecimiento de alimentos, ni problemas de ingresos a lo largo del año.

La opinión de varones y mujeres coincide también en la valoración de otros aspectos de sus condiciones de vida. Por ejemplo, al valorar la calidad de la construcción de las viviendas, el 51,8\% de los varones y el $51,4 \%$ de las mujeres señaló que la calidad de la construcción es buena; el 38,8\% de los varones y el 40,2\% de las mujeres indicó una calidad regular; mientras que el 9,4\% de los varones y el $8,4 \%$ de las mujeres la valoró como mala. 
Adicionalmente, los y las encuestadoras observaron las condiciones de la vivienda y registraron información respecto al tipo de materiales de construcción utilizado en las viviendas. La Tabla 3 muestra lo observado.

De acuerdo a lo observado, un poco más de la mitad de las viviendas tiene piso de tierra, casi la mitad tiene paredes de madera, y la mayoría cuenta con techo de zinc. El 83\% de las viviendas cuenta con cocina dentro de la casa, pero menos de la mitad (44\%) tiene un pozo para abastecerse de agua. La mayoría (92\%) tiene cercada el área de la vivienda y dispone de letrinas tradicionales (93\%), aunque un $5 \%$ cuenta con inodoros (con tanques de agua).

El uso de algunos equipos y herramientas también permite caracterizar la condición de los hogares. $\mathrm{El}$ radio y los celulares son los equipos que tienen mayor presencia en los hogares. El 88\% de los hogares dispone de radio, y el 77\% informó de la existencia de un celular en la casa. En el acceso a electrodomésticos, menos de la mitad (46\%) de los hogares reportó tener TV, y solo el 16\% de los hogares cuenta con una refrigeradora. El 13\% de las viviendas cuenta con paneles solares para proveerse de energía eléctrica. En medios para la movilización, el 32\% de los hogares reportó al menos una bicicleta y el 17\% indicó disponer de motocicleta (en ambos casos, mayormente usados por los varones). El resto de equipos y electrodomésticos son usados indistintamente por el hombre o la mujer.

\section{Tabla 3. Observación sobre las condiciones físicas de la vivienda de las personas encuestadas}

\begin{tabular}{llc}
\hline Variable & Tipo & Porcentaje \\
\hline \multirow{2}{*}{ Piso } & Tierra & 55 \\
\cline { 2 - 3 } & Cemento & 33 \\
\hline \multirow{2}{*}{ Paredes } & Madera & 47 \\
\cline { 2 - 3 } & Concreto & 25 \\
\cline { 2 - 3 } & Adobe & 22 \\
\hline \multirow{2}{*}{ Techo } & Zinc & 74 \\
\cline { 2 - 3 } & Teja & 11 \\
\cline { 2 - 3 } & Zinc y teja & 13 \\
\hline
\end{tabular}

Fuente: Encuesta a hogares con acceso a bosques en Nueva Segovia, Matagalpa, Jinotega y Río San Juan

\subsection{Actividades económicas de los hogares}

La encuesta se enfocó en identificar las actividades económicas que realizan los hogares y el nivel de importancia que cada una de ellas representa. Entre las actividades se consideran al menos doce: 1 ) agricultura de subsistencia, 2) venta de productos agrícolas, 3) venta de ganado o productos pecuarios, 4) crianza de aves de corral, 5) crianza de cerdos, 6) pesca, 7) caza, 8) producción forestal, 9) asalariado temporal, 10) comercio, 11) asalariado fijo y 12) remesas. Las actividades con mayor relevancia mencionadas por las personas encuestadas se resumen en la Tabla 4, presentadas por sexo, donde se incluye la valoración sobre la importancia atribuida.

La tabla muestra los porcentajes de respuestas por encima del $12 \%$. Al momento de verificar si las diferencias entre las respuestas de las mujeres y los varones son estadísticamente significativas los resultados indicaron que no lo son. Solo en el caso de la pesca y las remesas, dos actividades mencionadas por pocos hogares (61 hogares en el caso de la pesca y 72 en el caso de quienes reciben remesas), las diferencias entre las respuestas de mujeres y hombres sí demuestran diferencias estadísticas significativas. Es decir, para los hombres, la pesca y las remesas son actividades más relevantes que para las mujeres (ver anexo). La explicación puede estar asociada a que la pesca en ríos que suele hacerse en las comunidades la practican más los hombres, y es probable que sean los varones quienes reciben o deciden sobre las remesas.

Al comparar la actividad económica con la condición en que se definen los hogares según la pobreza, se identifican cinco actividades según si se trata de un hogar pobre o no, a través de diferencias estadísticas significativas. La agricultura de subsistencia, la producción forestal, el asalariado temporal, el comercio y las remesas son las actividades que hacen diferencias según la condición del hogar. La agricultura de subsistencia constituye un medio de vida rural relevante para un porcentaje de hogares en países en desarrollo donde la tala de pequeñas áreas de bosque natural permite sembrar maíz, arroz, yuca y bananos (Babigumira, et al., 2014). Para un hogar pobre, según nuestra encuesta, la agricultura es mucho más relevante que para uno no pobre 
Tabla 4. Grado de importancia atribuida a las principales actividades en el hogar

\begin{tabular}{|c|c|c|c|c|c|c|}
\hline \multirow[t]{2}{*}{$\begin{array}{l}\text { Principales } \\
\text { actividades }\end{array}$} & \multirow[t]{2}{*}{$\begin{array}{l}\text { Sexo del } \\
\text { entrevistado }\end{array}$} & \multirow{2}{*}{$\begin{array}{l}\text { Porcentaje } \\
\text { que realiza } \\
\text { la actividad }\end{array}$} & \multicolumn{4}{|c|}{$\begin{array}{l}\text { Importancia de la actividad para el sustento familiar, } \\
\text { según sexo del entrevistado }\end{array}$} \\
\hline & & & $\begin{array}{l}\text { Más } \\
\text { importante }\end{array}$ & Importante & $\begin{array}{l}\text { Menos } \\
\text { importante }\end{array}$ & $\begin{array}{l}\text { No } \\
\text { importante }\end{array}$ \\
\hline \multirow{2}{*}{$\begin{array}{l}\text { Agricultura de } \\
\text { subsistencia }\end{array}$} & Varones & $65,7 \%$ & $55,2 \%$ & $42,9 \%$ & $1,9 \%$ & \\
\hline & Mujeres & $68,0 \%$ & $60,9 \%$ & $36,9 \%$ & $2,1 \%$ & \\
\hline \multirow{2}{*}{$\begin{array}{l}\text { Venta de productos } \\
\text { agrícolas }\end{array}$} & Varones & $64,6 \%$ & $77,5 \%$ & $18,6 \%$ & $3,9 \%$ & \\
\hline & Mujeres & $62,5 \%$ & $71,3 \%$ & $23,6 \%$ & $4,0 \%$ & $1,1 \%$ \\
\hline \multirow{2}{*}{$\begin{array}{l}\text { Crianza de aves de } \\
\text { corral }\end{array}$} & Varones & $58,3 \%$ & $10,8 \%$ & $75,1 \%$ & $10,8 \%$ & $3,4 \%$ \\
\hline & Mujeres & $58,5 \%$ & $10,1 \%$ & $71,5 \%$ & $15,6 \%$ & $2,8 \%$ \\
\hline \multirow[t]{2}{*}{ Crianza de cerdos } & Varones & $33,2 \%$ & $5,4 \%$ & $74,6 \%$ & $16,2 \%$ & $3,8 \%$ \\
\hline & Mujeres & $32,7 \%$ & $6,0 \%$ & $69,8 \%$ & $16,5 \%$ & $7,7 \%$ \\
\hline \multirow{2}{*}{$\begin{array}{l}\text { Venta de ganado } \\
\text { o productos } \\
\text { pecuarios }\end{array}$} & Varones & $32,5 \%$ & $58,6 \%$ & $35,4 \%$ & $4,4 \%$ & $1,7 \%$ \\
\hline & Mujeres & $32,0 \%$ & $57,3 \%$ & $34,3 \%$ & $6,2 \%$ & $2,2 \%$ \\
\hline \multirow{2}{*}{$\begin{array}{l}\text { Asalariado } \\
\text { temporal }\end{array}$} & Varones & $28,5 \%$ & $58,5 \%$ & $34,0 \%$ & $5,0 \%$ & $2,5 \%$ \\
\hline & Mujeres & $26,4 \%$ & $54,4 \%$ & $36,1 \%$ & $8,2 \%$ & $1,4 \%$ \\
\hline \multirow[t]{2}{*}{ Producción forestal } & Varones & $20,8 \%$ & $8,6 \%$ & $48,3 \%$ & $40,5 \%$ & $2,6 \%$ \\
\hline & Mujeres & $16,7 \%$ & $6,5 \%$ & $54,8 \%$ & $36,6 \%$ & $2,2 \%$ \\
\hline \multirow[t]{2}{*}{ Comercio } & Varones & $12,2 \%$ & $69,1 \%$ & $20,6 \%$ & $2,9 \%$ & $7,4 \%$ \\
\hline & Mujeres & $13,5 \%$ & $62,7 \%$ & $26,7 \%$ & $8,0 \%$ & $2,7 \%$ \\
\hline
\end{tabular}

Fuente: Encuesta a hogares con acceso a bosques en Nueva Segovia, Matagalpa, Jinotega y Río San Juan

(ver Anexo 4), lo cual a menudo se asume como parte de la actividad de subsistencia. De igual maner, la producción forestal es una actividad de relevancia para los hogares pobres y no pobres, pero no para los catalogados como más pobres (ver Anexo 5). El salario temporal también resulta ser relevante para los hogares muy pobres y pobres (ver Anexo 6), particularmente para los muy pobres que tienen menos tierra y necesitan más que los otros de ingresos por la realización del trabajo temporal. El comercio (ver Anexo 7) y las remesas (ver Anexo 8) como actividades económicas son más relevantes para los hogares no pobres en comparación con los otros dos grupos.

Lo anterior permite señalar que hay una correspondencia entre el nivel de pobreza de los hogares y la importancia de la actividad forestal, sola o en combinación con otras actividades, como ya ha sido corroborado por las investigaciones realizadas por CIFOR en el marco del proyecto
Pobreza y Medio Ambiente (conocido por la sigla en inglés "PEN", que significa 'Poverty Environment Network'). ${ }^{7}$ El aprovechamiento forestal como medio de vida se incorpora en hogares rurales ya sea porque son afectados por una escasez de productos agrícolas, porque hay ausencia de algún tipo de recursos en los hogares, o porque hay oportunidad de mercado aunque ello no implica necesariamente que vuelquen todos sus esfuerzos en este sentido (Wunder, et al., 2014). Tampoco significa que son los más pobres los que tienden a aprovechar más el bosque, ya que esta actividad implica tener cierta disponibilidad de algunos recursos (ibid); lo cual coincide con nuestros hallazgos. La prueba de la

7 Este proyecto fue lanzado en septiembre del 2004 por CIFOR con el objetivo de recolectar datos socioeconómicos y ambientales de manera uniforme y consistente para crear una base de datos de 8301 hogares en 334 comunidades en 24 países. Ver más información al respecto en el sitio https:// data.cifor.org/dataset.xhtml?persistentId=doi:10.17528/ CIFOR/DATA.00021 
diferencia significativa en la encuesta solo reconoce que la distribución de respuestas dadas entre las dos variables (la actividad y la condición del hogar) es independiente y muestra un patrón en la relación entre ambas variables. Es decir, algunas actividades se relacionan más con uno o dos grupos (muy pobres, pobres) que con el resto. A continuación, los resultados respecto a la tierra y la herencia.

\subsection{Tenencia de la tierra y costumbres sobre la herencia en los hogares}

Los hogares muy pobres en la encuesta tienen menos tierra que los hogares pobres, pero los no pobres tienen más tierra que el resto, como presenta la Tabla 5.

El rango de tamaño de tierra con fines agrícolas para el 70\% de los hogares oscila entre menos de 1 y 7 hectáreas, mientras que las áreas de bosques privados dentro de sus propiedades oscilan entre 0,1 y 62 hectáreas.

El $81 \%$ de los varones y el $86 \%$ de las mujeres encuestadas afirmaron que la tenencia de los bosques a los cuales tienen acceso es de tipo privada. Las áreas de bosque nacional fueron reconocidas solo por el $18 \%$ de los varones y el $13 \%$ de las mujeres. El reconocimiento del área de bosque comunitario es aún menor, dado que menos del 3\% de los entrevistados (mujeres y varones) señaló que el dueño del bosque es la comunidad. La propiedad privada de la mayor parte de los bosques es relevante en comparación con otros países de Centroamérica (ver Panorama ambiental, Estado de la Región, 2011). En contraste, en la encuesta llevada a cabo en la RACCN, el 98\% señaló que los bosques son comunales.

Tabla 5. Promedio de tierra en el hogar según condición de pobreza

\begin{tabular}{lc}
\hline $\begin{array}{l}\text { Autopercepción } \\
\text { de pobreza }\end{array}$ & $\begin{array}{c}\text { Promedio del } \\
\text { área tierra (ha) }\end{array}$ \\
\hline Muy pobre & 5,2 \\
\hline Pobre & 9,1 \\
\hline No pobre & 25,2 \\
\hline Total & 12,5 \\
\hline
\end{tabular}

Fuente: Encuesta a hogares con acceso a bosques en Nueva Segovia, Matagalpa, Jinotega y Río San Juan
Al mismo tiempo, identificamos una relación entre la tenencia de la tierra y las costumbres sobre el traspaso de derechos. Las prácticas de transferencia de derechos de propiedad por medio de la herencia de la tierra no son neutrales a las normas de género y pueden estar o no influenciadas por el marco jurídico establecido, que a la vez puede o no estar sesgado por las normas culturales relativas al género.

Las mujeres y los hombres coincidieron en el $89 \%$ de los casos (igual porcentaje en cada sexo) en que en sus familias existe la costumbre de heredar los derechos sobre la tierra, y el ejercicio del derecho corresponde principalmente al varón como esposo, como muestran los datos en la Tabla 6.

El 80\% de los varones respondió que es el esposo quien hereda el derecho a la tierra en el hogar, y un poco más de la mitad reconoció que el derecho a heredar es también de la esposa. Las mujeres coincidieron con los varones en la forma de responder. Esta respuesta probablemente está relacionada con el hecho de que, al morir el esposo, la tierra queda para ellas, puesto que los hijos y las hijas tuvieron porcentajes menores de respuesta. Para aquellos que mencionaron derechos de herencia a los hijos y las hijas, los datos muestran que hay mayor inclinación hacia los hijos varones que hacia las hijas.

Tabla 6. ¿Quiénes heredan los derechos de herencia a la tierra en la familia? (Múltiples respuestas posibles)

\begin{tabular}{lrrrr}
\hline \multirow{2}{*}{$\begin{array}{l}\text { ¿Quién } \\
\text { hereda la } \\
\text { tierra? }\end{array}$} & Indicador & \multicolumn{2}{c}{ Encuestados } & Total \\
\cline { 2 - 4 } & & Varones & Mujeres & \\
\hline El esposo & $\mathrm{N}$ & 418 & 416 & 824 \\
\cline { 2 - 4 } & $\%$ & 80,5 & 75,3 & 77,91 \\
\hline La esposa & $\mathrm{N}$ & 285 & 302 & 587 \\
\cline { 2 - 4 } & $\%$ & 54,9 & 56 & 55,5 \\
\hline Las hijas & $\mathrm{N}$ & 42 & 57 & 99 \\
\cline { 2 - 4 } & $\%$ & 8,1 & 10,6 & 9,4 \\
\hline Los hijos & $\mathrm{N}$ & 70 & 82 & 152 \\
\cline { 2 - 4 } & $\%$ & 13,5 & 15,2 & 14,4 \\
\hline
\end{tabular}

Fuente: Encuesta a hogares con acceso a bosques en Nueva Segovia, Matagalpa, Jinotega y Río San Juan 
$\mathrm{Al}$ relacionar la variable de la herencia con la variable de autopercepción de pobreza sobre sus hogares, los hogares pobres y no pobres reconocen en mayor porcentaje el derecho de las esposas. De esta manera, se puede concluir que más de la mitad de los varones y las mujeres de la encuesta hacen un reconocimiento al derecho de la esposa a la herencia, aunque en un porcentaje inferior respecto al derecho de herencia de los esposos. El reconocimiento es importante, pero no suficiente si no se acompaña de una política de distribución equitativa (Fraser, 2007) para reducir la brecha que separa a las mujeres de los hombres en sus derechos a la tierra.

En la siguiente sección se aborda la participación y la forma en que se toman las decisiones sobre los productos del bosque, mostrando los sesgos y las brechas de género existentes.

\subsection{Las diferencias de género en el aprovechamiento del bosque}

El aprovechamiento del bosque es regulado por la ley y por las políticas forestales, aunque estas no siempre abordan la complejidad del sector forestal en cuanto a su composición. Las regulaciones de manejo y extracción suelen estar diseñadas de manera estándar para operaciones de diferentes escalas, sin considerar las diferencias existentes entre distintos dueños de bosques (Contreras, 2011). En este sentido, la extracción y el manejo de pequeñas áreas de bosques se rigen de la misma manera que en grandes extensiones. Esto no solo constituye una barrera para los y las propietarias de bosques en pequeñas áreas, sino que tiene restricciones implícitas para la participación de mujeres, dadas las múltiples tareas y restricciones de tiempo asociadas a ellas que estas implican, así como el escaso acceso a información y el conocimiento forestal "validado por los externos". Por un lado, está la carga de trabajo que ellas asumen para el cuidado de la familia, y, por otro lado, el tiempo que se necesita para hacer múltiples gestiones y trámites exigidos para el manejo forestal, sumado a los estereotipos que se construyen sobre las mujeres que se ausentan de sus hogares.

En la encuesta, el 98\% de los hogares hace aprovechamiento a partir de la extracción de productos del bosque. La mayoría extrae en bosques privados cuya cercanía al hogar es un aspecto sustantivo. Para el $75 \%$ de las personas, la distancia que separa la casa del bosque es de menos de un kilómetro, mientras que para el 21\%, la distancia es de hasta 5 kilómetros. El 3\% de los hogares se ubican a 10 kilómetros del bosque o menos, y un $1 \%$ a más de 10 kilómetros. En cambio, en las comunidades indígenas la extracción se hace en bosques comunitarios que se encuentran separados y distantes de la comunidad. Aquí, el $22 \%$ de los hogares recorre menos de 5 kilómetros para acceder al bosque, el 40,7\% debe moverse entre 6 y 10 kilómetros, y el 37\% debe recorrer más de 11 kilómetros. A menudo, la distancia se convierte en un factor de restricción para la movilidad de las mujeres al ver comprometido el uso del tiempo entre las responsabilidades en el hogar, el tiempo requerido para acceder a los bosques, y las especulaciones o preocupaciones sobre ellas cuando se trasladan a sitios distantes. Por ejemplo, se duda si las mujeres se han ido a trabajar y ganar dinero, o a buscar marido. Este tipo de duda ejerce una influencia directa como restricción en muchos casos para la movilidad de las mujeres que no quieren exponerse a la opinión sesgada por la interiorización de los roles de género en la comunidad. Adicionalmente, a los padres les preocupa que sus hijas puedan convertirse en madres solteras y aumentar las responsabilidades para ellos (comunicación personal, 22 junio 2016, técnico forestal supervisando extracción de resina de pino).

La leña es el principal recurso extraído ( $91 \%$ de los hogares) seguido de postes y agua (54\%), madera para diferentes usos $(29 \%)$, frutas silvestres $(12 \%)$, animales silvestres $(6,5 \%)$ y forrajes (4\%) (ver Tabla 7). La leña y los postes son dos productos del bosque relevantes para las familias en estos departamentos. Estos datos coinciden con el reporte de principales usos del inventario forestal nacional (INAFOR, 2009). Hay diferencias importantes con los datos de la extracción de los principales recursos forestales en la encuesta aplicada a comunidades indígenas, donde el 83\% de los hogares señaló que aprovechan la leña, seguido de la madera (52\%), los animales silvestres (43\%), los postes (39\%) y la extracción de frutas silvestres (37\%) (Alwang 2012, reporte interno). A pesar de que más hogares de la encuesta de las otras regiones parecen aprovechar leña y postes, en la RACCN, muchos más hogares aprovechan la madera (51\% frente a $29 \%$ ) y frutas silvestres 
(36\% frente a $12 \%$, o tres veces más), con la diferencia más grande en aprovechamiento de animales silvestres ( $42 \%$ frente a menos del $7 \%$, o seis veces más). Esto se debe probablemente al estado de los bosques naturales en la Costa y también a las tradiciones culturales en la relación humano-naturaleza.

Los hombres están a cargo de la extracción de casi todos los recursos. En ambas encuestas, la participación de mujeres en la extracción de recursos es porcentualmente menor a la de los hombres. Sin embargo, el porcentaje de extracción realizado por miembros de ambos sexos es mayor al hecho únicamente por mujeres. Por ejemplo, en el caso de la leña (el recurso de mayor extracción) los datos revelan que solo un 3\% de las mujeres lleva leña a los hogares sin la participación de varones. Este porcentaje es el mismo tanto para mujeres no-indígenas y mujeres indígenas. No obstante, en la encuesta en los cuatro departamentos, para el
$14 \%$ de las mujeres y para el $11 \%$ de los varones extraer leńa es una actividad compartida, es decir, tanto ellas como ellos extraen este producto. Este hallazgo de trabajo de extracción de productos del bosque conjunta entre las mujeres y los varones es un aspecto que no se investigó en la encuesta del Caribe Norte y es un aspecto que amerita mayor estudio para comprender las implicaciones que tiene tanto en la participación de las mujeres como en su aparente invisibilidad en la extracción de recursos.

La extracción de algunos productos compartida por ambos (hombres y mujeres) tiene un comportamiento similar a los datos encontrados por Sunderland, et al. (2014) en América Latina, donde esta categoría tiene más peso porcentual al compararla con el porcentaje de ciertos productos, como la caza de animales para la obtención de carne, y la extracción de forrajes y fibras, que son únicamente extraídos por las mujeres.

Tabla 7. Mujeres y hombres en la extracción de productos del bosque

\begin{tabular}{|c|c|c|c|c|c|}
\hline \multirow{3}{*}{$\begin{array}{l}\text { Principales recursos que las } \\
\text { familias extraen/usan }\end{array}$} & \multirow{3}{*}{$\begin{array}{l}\text { ¿Quién extrae el } \\
\text { producto? }\end{array}$} & \multicolumn{4}{|c|}{ Repuestas de las y los entrevistados } \\
\hline & & \multicolumn{2}{|c|}{ Hombres } & \multicolumn{2}{|c|}{ Mujeres } \\
\hline & & $\mathbf{N}$ & Porcentaje & $\mathbf{N}$ & Porcentaje \\
\hline \multirow[t]{3}{*}{ Leña } & Hombre & 436 & $74,80 \%$ & 438 & $72,40 \%$ \\
\hline & Mujer & 14 & $2,40 \%$ & 25 & $4,10 \%$ \\
\hline & Ambos & 63 & $10,80 \%$ & 89 & $14 \%$ \\
\hline \multirow[t]{3}{*}{ Postes } & Hombre & 279 & $47,90 \%$ & 297 & $49,10 \%$ \\
\hline & Mujer & 5 & $0,90 \%$ & 12 & $2 \%$ \\
\hline & Ambos & 20 & $3,40 \%$ & 18 & $3 \%$ \\
\hline \multirow[t]{3}{*}{ Madera } & Hombre & 155 & $26,60 \%$ & 127 & $21 \%$ \\
\hline & Mujer & 2 & $0,30 \%$ & 10 & $1,70 \%$ \\
\hline & Ambos & 19 & $3,30 \%$ & 25 & $4 \%$ \\
\hline \multirow[t]{3}{*}{ Frutas Silvestres } & Hombre & 25 & $4,30 \%$ & 33 & $6 \%$ \\
\hline & Mujer & 1 & $0,20 \%$ & 5 & $0,80 \%$ \\
\hline & Ambos & 27 & $4,60 \%$ & 50 & $8 \%$ \\
\hline \multirow[t]{3}{*}{ Animales Silvestres } & Hombre & 28 & $4,80 \%$ & 32 & $5,30 \%$ \\
\hline & Mujer & 1 & $0,20 \%$ & 0 & $0 \%$ \\
\hline & Ambos & 7 & $1,20 \%$ & 4 & $0,70 \%$ \\
\hline \multirow[t]{3}{*}{ Material para artesanía } & Hombre & 3 & $0,50 \%$ & 0 & $0 \%$ \\
\hline & Mujer & 5 & $0,90 \%$ & 7 & $1,20 \%$ \\
\hline & Ambos & 2 & $0,30 \%$ & 2 & $0,30 \%$ \\
\hline
\end{tabular}

Fuente: Encuesta a hogares con acceso a bosques en Nueva Segovia, Matagalpa, Jinotega y Río San Juan 
$\mathrm{Al}$ analizar la extracción de recursos por la condición de pobreza de los hogares, como se mencionó antes, las respuestas indican que la extracción de madera es más relevante entre los hogares no pobres y pobres. En los hogares no pobres, aproximadamente el 38\% extrae madera, en los pobres, $28 \%$, y el porcentaje cae a $12 \%$ entre los muy pobres. De igual manera, la extracción de postes resulta más relevante para los hogares no pobres y pobres que para los muy pobres, lo cual está asociado directamente a que tienen menos disponibilidad de tierra. Sin embargo, ello no omite la posibilidad de que, aunque tengan tales restricciones, estas les inhiban de gestionar otros recursos para la extracción forestal ya que, como reportó Wunder, et al. (2014), muchos de los productos forestales se extraen de bosques nacionales.

Por otra parte, dos actividades de aprovechamiento forestal son también el uso de material vegetativo y la recolección de frutas silvestres. En la primera, si bien la extracción de material vegetativo para la elaboración de artesanías fue reportada en pocos hogares, esta actividad resultó ser estadísticamente relevante para los hogares más pobres (y en particular para las mujeres), sugiriendo que es este grupo quien se involucra en la elaboración de artesanías. Esto probablemente se da por no tener acceso a otros recursos (financieros, equipos, etc.) para el aprovechamiento forestal, ya que al menos pueden usar sus manos y su imaginación para elaborar productos para generarse ingresos. La segunda actividad, la recolección de frutas silvestres, también es realizada por muy pocos. En general, las mujeres hacen una menor extracción de algunos recursos del bosque. Ese aprovechamiento, aunque pequeño porcentualmente, es una actividad que comparten con los varones y no una actividad realizada por los varones únicamente.

En resumen, el producto que más extraen los hombres del bosque es la leña, seguido por postes, madera, frutas y animales. Las mujeres extraen más leña, seguida por fruta silvestre, postes, y madera. Hay muy poca participación de las mujeres en la caza de animales. También es notable que las mujeres reportan que su participación en la extracción de recursos es ligeramente mayor a la reconocida por los hombres, tanto en la extracción realizada exclusivamente por ellas como en la realizada por ambos hombres y mujeres, en todos los productos menos en la caza de animales silvestres. Esto coincide con los planteamientos de la FAO respecto a la invisibilidad de las mujeres en el manejo de recursos forestales.

La extracción de los productos del bosque tiene como finalidad principal el consumo en los hogares, un dato que ha sido confirmado en otros estudios globales sobre extracción de productos del bosque (ver, por ejemplo, Sunderland, et al., 2014). Solo el $14 \%$ de la encuesta dijo comercializar algunos productos, entre ellos madera (14\%), leña $(1,6 \%)$, postes $(2,4 \%)$ y frutas silvestres $(1,5 \%)$. Los datos de los hogares en las comunidades indígenas de la RACCN marcan una diferencia porcentual importante en este aspecto en tanto la extracción también se utiliza para comercializar. Por ejemplo, un tercio de los hogares venden madera, $17 \%$ venden animales silvestres y $13 \%$ y $12 \%$ respectivamente venden frutas silvestres y postes. En menor medida se venden también leña, material para artesanía, hierbas y miel.

En las dos encuestas se preguntó de entre los que venden algún producto, quién tiene dicha responsabilidad de vender y también quién decide sobre el dinero, aunque con diferencias en la manera de abordar esta segunda pregunta entre una y otra encuesta como pueden verse en la última columna de las Tablas 8 y $9 .{ }^{8}$

En la tabla 8 se puede apreciar la manera en que respondieron las mujeres y los varones de los hogares encuestados según quién está a cargo de la venta y quién decide en el hogar en los cuatro departamentos. Las respuestas de los hombres son principalmente a favor de sí mismos reafirmando su protagonismo, o bien incluyen a la mujer indicando que es una tarea de ambos. Muy pocos varones reconocen que las mujeres tienen alguna responsabilidad en la venta, contrario a la opinión de las mujeres que suelen dividir sus respuestas afirmando que la mayor responsabilidad corresponde efectivamente a los varones, pero también ubicándose ellas mismas con algún nivel de responsabilidad o indicando que la responsabilidad es compartida.

8 Es preciso recordar que ambas encuestas tuvieron algunas diferencias, por ejemplo, en la encuesta de los cuatro departamentos se encuestó a dos personas del mismo hogar con preferencia hombre-mujer, mientras que en la encuesta de las comunidades indígenas se encuestó a hombres y mujeres de hogares distintos, lo que hace que las tablas de resultados sobre la venta y decisión sobre el dinero no se construyan exactamente de la misma manera. 
Tabla 8. Productos del bosque, quién vende y quién decide cómo utilizar el dinero en los cuatros departamentos

\begin{tabular}{|c|c|c|c|c|c|c|c|}
\hline \multirow[t]{2}{*}{$\begin{array}{l}\text { Productos del } \\
\text { bosque }\end{array}$} & \multirow[t]{2}{*}{$\begin{array}{l}\text { ¿Quién lo } \\
\text { hace? }\end{array}$} & \multicolumn{3}{|c|}{$\begin{array}{l}\text { De los que venden, ¿quién es } \\
\text { responsable de la venta del producto, } \\
\text { según el sexo del entrevistado? }\end{array}$} & \multicolumn{3}{|c|}{$\begin{array}{c}\text { ¿Quién decide cómo utilizar las } \\
\text { ganancias, según el sexo del } \\
\text { entrevistado? }\end{array}$} \\
\hline & & Varones & Mujeres & Total & Varones & Mujeres & Total \\
\hline \multirow[t]{3}{*}{ Leña } & Hombre & $85,7 \%$ & $75,0 \%$ & $80,0 \%$ & $57,1 \%$ & $50,0 \%$ & $53,3 \%$ \\
\hline & Mujer & & $12,5 \%$ & $6,7 \%$ & & & \\
\hline & Ambos & $14,3 \%$ & $12,5 \%$ & $13,3 \%$ & $42,9 \%$ & $50,0 \%$ & $46,7 \%$ \\
\hline \multirow[t]{3}{*}{ Postes } & Hombre & $100,0 \%$ & $66,7 \%$ & $84,6 \%$ & $85,7 \%$ & $50,0 \%$ & $69,2 \%$ \\
\hline & Mujer & & $33,3 \%$ & $15,4 \%$ & & $16,7 \%$ & $7,7 \%$ \\
\hline & Ambos & & & & $14,3 \%$ & $33,3 \%$ & $23,1 \%$ \\
\hline \multirow[t]{3}{*}{ Madera } & Hombre & $80,0 \%$ & $76,2 \%$ & $78,3 \%$ & $60,0 \%$ & $57,1 \%$ & $58,7 \%$ \\
\hline & Mujer & & & & $4,0 \%$ & $4,8 \%$ & $4,3 \%$ \\
\hline & Ambos & $20,0 \%$ & $23,8 \%$ & $21,7 \%$ & $36,0 \%$ & $38,1 \%$ & $37,0 \%$ \\
\hline \multirow{3}{*}{$\begin{array}{l}\text { Frutas } \\
\text { Silvestres }\end{array}$} & Hombre & $71,4 \%$ & $44,4 \%$ & $56,3 \%$ & $71,4 \%$ & $22,2 \%$ & $43,8 \%$ \\
\hline & Mujer & & $22,2 \%$ & $12,5 \%$ & & $11,1 \%$ & $6,3 \%$ \\
\hline & Ambos & $28,6 \%$ & $33,3 \%$ & $31,3 \%$ & $28,6 \%$ & $66,7 \%$ & $50,0 \%$ \\
\hline
\end{tabular}

Fuente: Encuesta a hogares con acceso a bosques en cuatro departamentos: Nueva Segovia, Matagalpa, Jinotega y Río San Juan

En la responsabilidad de venta de productos como leña, postes, madera y frutas, pocos varones reconocieron el involucramiento de las mujeres, pero ellas sí lo hacen de manera explícita, con excepción en la venta de madera donde coinciden con los varones en que esta responsabilidad es mayormente de ellos, y que las mujeres no venden solas. La negación o no de la responsabilidad de las mujeres en la venta de productos del bosque está íntimamente relacionada con las maneras en que unos y otras ven sus roles de género tanto en el ámbito del hogar como en el vínculo con el mercado. Mientras que los varones no visualizan a las mujeres en la responsabilidad de manejar productos de los bosques para su contacto con el mercado, las mujeres sí lo manifiestan. En la encuesta de las comunidades indígenas, las mujeres como individuos alcanzan un porcentaje mayor de responsabilidad que las no indígenas en la venta y en el control del dinero, en particular en la venta de material para artesanías, hierbas, miel y postes. El control del dinero de la venta parece ser más compartido entre ambos tal como señalan los datos de la tabla siguiente (ver Tabla 9, comparar con las columnas "Total" en Tabla 8).
En ambas tablas (8 y 9), es notorio que la venta de productos es una responsabilidad más para los hombres que para las mujeres, lo que coincide con el planteamiento de la FAO (2013) respecto a que es una tendencia en los países de la región. ${ }^{9}$ Los hombres dominan la extracción y venta en los principales productos, como la madera, los postes, la leña y los animales silvestres. Sin embargo, las mujeres predominan en la artesanía y las hierbas, particularmente en comunidades indígenas. ${ }^{10} \mathrm{La}$ responsabilidad de vender puede ser de manera individual (por hombre o mujer), pero a la vez puede ser una responsabilidad compartida. Un punto notable es que -aunque son pocos hogares indígenas que venden frutas silvestres, artesanía, hierbas y miel- los datos demuestran que las mujeres tienen más control sobre los fondos de la venta en estas actividades donde su participación

9 No obstante, el estudio de Sunderland, et al. (2014) afirma que hay una diferencia de género por región. En América Latina los varones predominan tanto en la extracción como en la comercialización y generación de ingresos de los productos forestales, pero esto es distinto en otras regiones del mundo.

10 Con respecto a las frutas silvestres, las respuestas no coinciden entre las dos encuestas. 
Tabla 9. Productos del bosque, quién es responsable de las ventas y del control del dinero de la venta en comunidades indígenas

\begin{tabular}{|c|c|c|c|c|c|c|c|}
\hline \multirow[t]{2}{*}{ Recurso } & \multirow[b]{2}{*}{ Total } & \multicolumn{3}{|c|}{ De los que venden, ¿quién vende? } & \multicolumn{3}{|c|}{ ¿Quién controla el dinero de la venta? } \\
\hline & & Hombre & Mujer & Ambos & Hombre & Mujer & Ambos \\
\hline Madera & 33,3 & 55,6 & 37,4 & 7,0 & 28,3 & 20,2 & 51,5 \\
\hline Postes & 12,0 & 58,3 & 38,9 & 2,8 & 38,9 & 16,7 & 44,4 \\
\hline Leña & 5,7 & 35,3 & 23,5 & 41,2 & 17,6 & 11,8 & 70,6 \\
\hline $\begin{array}{l}\text { Animales } \\
\text { Silvestres }\end{array}$ & 16,7 & 40,8 & 26,5 & 32,6 & 20,4 & 22,4 & 57,1 \\
\hline Frutas silvestres & 12,7 & 23,7 & 36,8 & 39,5 & 13,2 & 39,5 & 47,4 \\
\hline $\begin{array}{l}\text { Material para } \\
\text { artesanía }\end{array}$ & 5,3 & 25,0 & 62,5 & 12,5 & 6,2 & 59,2 & 37,5 \\
\hline Hierbas & 3,7 & 36,4 & 45,4 & 18,2 & 18,2 & 54,6 & 27,3 \\
\hline Miel & 3,0 & 44,4 & 44,4 & 11,1 & 22,2 & 55,6 & 22,2 \\
\hline
\end{tabular}

Fuente: Datos de la encuesta de hogares indígenas en la RACCN, Alwang, 2012 (comunicación personal)

en la venta es igual o mayor que la de los varones (y también en los ingresos por la venta de carne de los animales silvestres).

En la encuesta se incluyeron preguntas para conocer la percepción de las personas encuestadas sobre el beneficio de la venta de productos forestales para hombres y mujeres por separado. Las preguntas pedían afirmar o negar si había beneficio o se habían incrementado las ganancias por la venta de los productos. Los resultados de la Tabla 10 muestran que, primero, hubo coincidencia de respuestas entre hombres y mujeres; segundo, hay beneficios del uso o venta de productos; tercero, las mujeres se benefician un poco más que los varones; $y$ cuarto, el aumento de las ganancias no parece ser diferente entre hombres y mujeres. Estos resultados difieren de las respuestas de la encuesta en las comunidades indígenas donde el 90\% señaló beneficios para las mujeres en el uso-venta y el $36 \%$ indicó beneficios para las mujeres en las ganancias. Ambos casos reflejan que las mujeres indígenas se benefician más de los productos del bosque que las mujeres no indígenas, lo que puede estar relacionado con la mayor importancia de los bosques en la vida de los hogares indígenas en general.
En conclusión, hay aprovechamiento del bosque más generalizado y más diversificado, además de mayor comercialización de los recursos del bosque, en la RACCN que en las otras regiones del país. Además, existen diferencias de género en el aprovechamiento de los recursos del bosque tanto en las comunidades indígenas como en el resto de comunidades del país. Los datos sobre la extracción de recursos revelan que, aunque los hombres dominan esta actividad tanto en el Caribe Norte como en el resto del país, las mujeres indígenas participan más que las mujeres no indígenas tanto en actividades realizadas únicamente por mujeres como en actividades compartidas con los varones. Las mujeres no indígenas, cuando participan, no hacen extracción individualizada de productos del bosque, ellas suelen hacerlo de manera conjunta con otro varón del hogar. La extracción compartida fue afirmada tanto por mujeres como por hombres, de tal manera que se precisa entender mejor ese proceso de compartir esta responsabilidad. Por la manera en que se estructuró la encuesta, no se puede conocer el funcionamiento de la relación compartida y las implicaciones que tiene para hombres y mujeres. Este es un aspecto que posteriores trabajos de investigación podrían profundizar. 
Tabla 10. Percepción sobre el beneficio de la venta de los productos forestales

\begin{tabular}{|c|c|c|c|c|}
\hline \multirow[t]{2}{*}{ Afirmaciones } & & \multicolumn{2}{|c|}{ Sexo del encuestado } & \multirow[t]{2}{*}{ Total } \\
\hline & & Varones & Mujeres & \\
\hline \multirow{2}{*}{$\begin{array}{l}\text { Los hombres se benefician del uso/venta de productos forestales } \\
\text { en esta comunidad }\end{array}$} & $\mathrm{N}$ & 214 & 221 & 435 \\
\hline & $\%$ & 36,7 & 36,5 & 36,6 \\
\hline \multirow{2}{*}{$\begin{array}{l}\text { Las ganancias de los hombres producto de la venta ha aumentado } \\
\text { en los últimos } 3 \text { años }\end{array}$} & $\mathrm{N}$ & 114 & 117 & 231 \\
\hline & $\%$ & 19,6 & 19,3 & 19,4 \\
\hline \multirow{2}{*}{$\begin{array}{l}\text { Las mujeres se benefician del uso/venta de productos forestales } \\
\text { en esta comunidad. }\end{array}$} & $\mathrm{N}$ & 227 & 239 & 466 \\
\hline & $\%$ & 38,9 & 39,5 & 39,2 \\
\hline \multirow{2}{*}{$\begin{array}{l}\text { Las ganancias de las mujeres producto de la venta de los } \\
\text { productos del bosque han aumentado en los últimos } 3 \text { años. }\end{array}$} & $\mathrm{N}$ & 112 & 115 & 227 \\
\hline & $\%$ & 19,2 & 19,0 & 19,1 \\
\hline
\end{tabular}

Fuente: Encuesta a hogares con acceso a bosques en Nueva Segovia, Matagalpa, Jinotega y Río San Juan

\subsection{Percepción sobre el estado de los productos del bosque}

El Mapa 1 mostró la situación general del país respecto a la imagen de pérdida de los bosques. En la medida en que se reducen las áreas boscosas, muchos productos se vuelven escasos, así lo confirmó el 95,4\% de encuestados de los cuatro departamentos y el 72,3\% de los hogares en las comunidades indígenas. Los dos productos menos abundantes en comparación con una década atrás en comunidades no indígenas son el agua y la leña entre una lista de 13 productos ${ }^{11}$. El agua y la leña son menos abundantes debido a la sobreexplotación realizada por miembros de la comunidad y por forasteros. En las comunidades indígenas, en cambio, el $76 \%$ de los hogares indicaron que los recursos son menos abundantes debido a las afectaciones de los fenómenos naturales. El último huracán (Félix) que impactó la región destruyó extensas áreas de bosques afectando no solo la flora, sino también la fauna y la vida de la población.

Las fuentes de agua a la que tienen acceso las familias son principalmente las fuentes superficiales (ríos, quebradas, ojos de agua). El $72 \%$ de mujeres y varones consideran que la sobreexplotación de la leña no solo se debe a su uso excesivo, sino también a la falta de control de la agencia nacional forestal. También señalaron que, si las autoridades lo permiten, los miembros de la comunidad no tienen poder para detener esa sobreexplotación. Esta

11 Madera, postes, leña, carbón, animales silvestres, frutas silvestres, material para artesanía, hierbas, miel, agua, tierra (incluye barro y arena), forraje y fibras. situación está implícitamente relacionada con las deficiencias institucionales en la gobernanza forestal (Contreras, 2011).

La encuesta también indagó la opinión de mujeres $y$ varones en cada hogar respecto a si estaban de acuerdo o en desacuerdo con estas cuatro afirmaciones:

- Los bosques deben ser protegidos,

- Mejorar la condición de los bosques locales es necesario porque contribuye al bienestar familiar,

- Mejorar la condición de los bosques locales es necesario para obtener aire limpio, conservar los suelos y el agua; $y$

- Para mejorar la condición de los bosques locales, mi familia y yo estamos dispuestos a reducir el consumo de productos forestales.

Para comparar si había diferencias en las respuestas de hombres y mujeres en sus hogares, en el procesamiento de los datos omitimos las repuestas de aquellos hogares donde los informantes eran del mismo sexo, es decir, comparamos las respuestas en aquellos hogares donde las dos personas encuestadas fueron de sexos opuestos. Los resultados indican que el 99,5 y 99,8\% de mujeres y varones, respectivamente, están de acuerdo con estas cuatro afirmaciones mostrando repuestas similares entre ambos. La coincidencia de respuesta es clara y confirma la percepción de responsabilidad de las propias familias en la preservación y manejo del recurso forestal como se expresa más adelante. De igual manera, opinaron a favor de reducir el consumo de productos forestales como mecanismo para ayudar a mejorar la condición de los bosques en sus comunidades. 
Tabla 11. Opiniones sobre acciones para mejorar las condiciones de los bosques en las comunidades indígenas

\begin{tabular}{lrrrr}
\hline Afirmaciones & & \multicolumn{2}{c}{ Están de acuerdo } & \multirow{2}{*}{ Total } \\
\cline { 2 - 4 } Resultado de las comunidades indígenas & & Varones & Mujeres & \\
\hline Los bosques deben ser protegidos & $\mathrm{N}$ & 141 & 154 & 295 \\
\cline { 2 - 4 } & $\%$ & 99 & 97 & 98,3 \\
\hline Mejorar la condición de los bosques locales es necesario porque & $\mathrm{N}$ & 22 & 43 & 65 \\
\cline { 2 - 4 } $\begin{array}{l}\text { contribuyen al bienestar familiar* } \\
\text { Mejorar la condición de los bosques locales es necesario para }\end{array}$ & $\mathrm{N}$ & 15,5 & 27,2 & 21,7 \\
\hline obtener aire limpio, conservar los suelos y el agua* & $\%$ & 84,5 & 72,8 & 78,3 \\
\hline Para mejorar la condición de los bosques locales, mi familia y yo & $\mathrm{N}$ & 134 & 137 & 271 \\
\cline { 2 - 4 } estamos dispuestos a reducir el consumo de productos forestales & $\%$ & 94,4 & 86,7 & 90,3 \\
\hline
\end{tabular}

Fuente: Datos de la encuesta de hogares indígenas en la RACCN, Alwang, 2012 (comunicación personal)

* Respondientes tenían que escoger entre estas dos respuestas.

En las comunidades indígenas las respuestas fueron similares con respecto a la primera pregunta (ver Tabla 11). Las siguientes dos preguntas fueron hechas de manera diferente: la persona encuestada tenía que escoger entre las dos afirmaciones. La gran mayoría dio mayor importancia a los servicios ambientales que a las contribuciones al bienestar familiar, a pesar de la importancia de los productos en los medios de vida de los hogares indígenas y de la relativa abundancia de los bosques en la región. En la última afirmación, la respuesta difiere también en el porcentaje con respecto a la encuesta en los cuatro departamentos. Es probable que los porcentajes sean inferiores dada la mayor disponibilidad de bosque existente en las comunidades indígenas.

$\mathrm{Al}$ mismo tiempo, se consultó a los varones si estaban de acuerdo o en desacuerdo con apoyar a sus esposas para mejorar la condición de los bosques locales. Una pregunta indagó con los varones si apoyarían a la esposa a contribuir en labores de replantación de árboles y si les apoyarían también en su involucramiento en labores de ronda. El 99,5\% de los varones afirmó estar de acuerdo. También se preguntó solo a las mujeres si para mejorar las condiciones locales de los bosques, ellas estarían dispuestas a contribuir en labores de replantación de árboles y en labores de ronda o patrullaje, y el $98 \%$ de las mujeres encuestadas dijo estar de acuerdo. Los porcentajes de respuestas en las comunidades indígenas fueron inferiores a los de la encuesta en los otros departamentos, quizá debido a las mayores condiciones para que la regeneración natural prospere con facilidad ${ }^{12}$; es un aspecto que amerita profundización. Los resultados también difieren considerando el sexo. El 78,7\% de los varones dijo que apoyaría a sus esposas, pero el $83,7 \%$ de las mujeres dijo que sí se involucraría. Estos datos muestran no solo opiniones favorables de los hombres y de las mujeres en su involucramiento en acciones que ayuden a mejorar las condiciones de los bosques, sino también revelan la manera en que conciben sus responsabilidades individuales.

Fuera de la RACCN, la responsabilidad de proteger los bosques fue atribuida, tanto por ellas como por ellos, en primera instancia a la propia comunidad, seguido por el gobierno local y la Policía Nacional. Desde esta perspectiva, atribuirse la responsabilidad a sí mismos implica de cierta manera una contradicción con lo establecido en el marco regulatorio que presenta como responsable al Estado. Probablemente por ello, también afirmaron que no pueden hacer mucho por cuenta suya cuando las autoridades tienen la responsabilidad de intervenir. Las opiniones de mujeres y varones coinciden en señalar que las partes interesadas para la creación de reglas para el acceso a los bosques son, en primera instancia, los propietarios y propietarias de los bosques, seguido de la Alcaldía y el gobierno nacional. Estos datos muestran la necesidad de abrir una discusión sobre los actores responsables establecidos en el marco regulatorio sobre los

12 O posiblemente por la percepción del peligro por conflictos actuales con colonos en la zona y la distancia de los bosques. 
recursos naturales, donde el Estado se atribuye la mayor responsabilidad ${ }^{13}$ y restringe la acción colectiva de quienes están cerca o viven de los bosques, principalmente los que son pequeños dueños de bosques. ${ }^{14}$ Lo mismo sucede en las comunidades indígenas que también atribuyen la responsabilidad de protección a la comunidad. ${ }^{15}$

\subsection{Los hogares en el manejo de los bosques}

En la sección anterior se presentaron percepciones de hombres y mujeres sobre el estado de los bosques y sobre su responsabilidad en la mejora de las condiciones de los bosques. Esta sección se enfoca en su participación o involucramiento directo en su gestión.

\subsubsection{Participación, contribución y decisiones sobre el manejo de los bosques}

Más de la mitad de mujeres y varones coinciden en que no solo han contribuido personalmente al manejo de los bosques, sino que también han tomado decisiones para el manejo de sus productos, aunque con diferencias en la manera en que respondieron las mujeres y los varones (ver Tabla 12).

Ellas, por ejemplo, perciben que su contribución en el manejo del bosque es inferior a la de los hombres,

13 Se señala incluso que "la protección de los recursos naturales del país son objeto de seguridad nacional, así como de las más elevada responsabilidad y prioridad del Estado" (artículo 1 ley 585) (Asamblea Nacional, 2006)

14 El artículo 47 del reglamento de la ley 462 para la conservación, fomento y desarrollo sostenible del sector forestal numeral 1 establece que para el aprovechamiento forestal en fincas con áreas boscosas menores de 10 hectáreas se debe obtener permiso de la autoridad forestal y previo a ello se requiere presentar un plan de reposición forestal que solo puede elaborar un regente forestal autorizado por el instituto forestal y que el propietario del área debe pagar. En caso de ceder los derechos de aprovechamiento a otra persona se debe presentar copia del derecho otorgado, lo cual debe hacerse con notario público. El artículo 55 del mismo reglamento señala que el aprovechamiento de árboles caídos por causas naturales en fincas debe contar con autorización previa del INAFOR. El artículo 57 indica que para el aprovechamiento de leña, cuando se trate de los residuos resultantes de las actividades productivas en fincas agrosilvopastoriles, debe contar también con el permiso del INAFOR (Asamblea Nacional, 2003).

15 La atribución dada por ley es referida al Instituto Forestal en coordinación con el Consejo Regional (ver ley 462, decreto 73-2003, ley 585).
Tabla 12. Contribución y toma de decisiones sobre los bosques

\begin{tabular}{lccc}
\hline \multirow{2}{*}{$\begin{array}{l}\text { En los últimos } \\
12 \text { meses ha: }\end{array}$} & \multicolumn{2}{c}{ Repuestas positivas } & \multirow{2}{*}{ Total } \\
\cline { 2 - 3 } & Varones & Mujeres & \\
\hline $\begin{array}{l}\text { ¿Contribuido al } \\
\text { manejo de los } \\
\text { bosques? }\end{array}$ & $\mathrm{N}=442$ & $\mathrm{~N}=390$ & $\mathrm{~N}=832$ \\
\cline { 2 - 4 } & $79,4 \%$ & $70,0 \%$ & $74,7 \%$ \\
\hline $\begin{array}{l}\text { ¿Tomado } \\
\text { decisiones sobre } \\
\text { el manejo de los } \\
\text { bosques? }\end{array}$ & $\mathrm{N}=344$ & $\mathrm{~N}=309$ & $\mathrm{~N}=653$ \\
\cline { 2 - 4 } & $61,8 \%$ & $55,5 \%$ & $58,6 \%$ \\
\hline $\begin{array}{l}\text { ¿Decidido quién } \\
\text { y quién no puede } \\
\text { entrar en el } \\
\text { bosque(s)? }\end{array}$ & $\mathrm{N}=416$ & $\mathrm{~N}=359$ & $\mathrm{~N}=775$ \\
\cline { 2 - 4 } & $74,7 \%$ & $64,5 \%$ & $69,6 \%$ \\
\hline
\end{tabular}

Fuente: Encuesta a hogares con acceso a bosques en Nueva Segovia, Matagalpa, Jinotega y Río San Juan

probablemente porque son mayormente los varones quienes más se involucran en el accionar relacionado con el manejo, como también en decidir quién entra y quién no entra en el bosque. La encuesta realizada en comunidades indígenas fue basada en el lapso del último mes; no en el año. Un poco más de la mitad de los hombres expresó haber contribuido o tomado decisiones sobre el manejo de los bosques, y un poco menos de la mitad de las mujeres; solo el $41 \%$ de los hombres y el $25 \%$ de las mujeres habían decidido quién puede entrar en el bosque. Las dos encuestas fueron similares en que, entre ellos y ellas, el menor porcentaje de respuestas positivas estuvo en el grupo de las mujeres.

Las actividades realizadas en los hogares para contribuir al manejo de los bosques resultaron ser: reforestación en la finca, reforestación en la comunidad, establecimiento y manejo de viveros, y/o el mejoramiento del bosque de alguna otra manera. La encuesta pidió diferenciar la contribución de las esposas y los esposos dentro de los hogares y los resultados atribuyen una contribución bastante mayor por parte de los esposos en todas estas actividades. Para los varones, en relación a la percepción de condición de pobreza, se nota que la participación en dichas actividades es mayor para los no pobres, seguido por los pobres, y después por los muy pobres, con la excepción de la siembra de árboles en zonas comunitarias, la cual es igual para todos (ver Tabla 13). La menor participación de los muy pobres puede estar relacionada a su menor disponibilidad de tierra y de tiempo. Sin embargo, se destaca que aun así, el 41\% reporta la siembra de árboles en su finca. 
Tabla 13. Acciones que realizan los esposos por tipo de hogar en condición de pobreza

\begin{tabular}{|c|c|c|c|c|c|c|}
\hline \multirow[t]{2}{*}{ Acciones del esposo que participa } & & \multicolumn{4}{|c|}{ Condición de pobreza del hogar* } & \multirow[t]{2}{*}{ Total } \\
\hline & & No opinó & Muy pobre & Pobre & No pobre & \\
\hline \multirow{2}{*}{$\begin{array}{l}\text { Ha participado en el establecimiento y } \\
\text { manejo de un vivero }\end{array}$} & $\mathrm{N}$ & 10 & 20 & 229 & 97 & 356 \\
\hline & $\%$ & 32,3 & 24,1 & 28,2 & 36,9 & 30,0 \\
\hline \multirow[t]{2}{*}{ Ha plantado árboles en su finca } & $\mathrm{N}$ & 9 & 34 & 406 & 144 & 593 \\
\hline & $\%$ & 29,0 & 41,0 & 50,1 & 54,8 & 49,9 \\
\hline \multirow{2}{*}{$\begin{array}{l}\text { Ha plantado árboles en zona forestal } \\
\text { comunitaria }\end{array}$} & $\mathrm{N}$ & 3 & 15 & 143 & 45 & 206 \\
\hline & $\%$ & 9,7 & 18,1 & 17,6 & 17,1 & 17,3 \\
\hline \multirow{2}{*}{$\begin{array}{l}\text { Ha mejorado la condición de los bosques en } \\
\text { alguna u otra forma }\end{array}$} & $\mathrm{N}$ & 6 & 10 & 234 & 80 & 330 \\
\hline & $\%$ & 19,4 & 12,0 & 28,9 & 30,4 & 27,8 \\
\hline
\end{tabular}

Fuente: Encuesta a hogares con acceso a bosques en Nueva Segovia, Matagalpa, Jinotega y Río San Juan

*Este porcentaje se refiere a las personas que se ubicaron en este grupo de pobreza y que participó en la actividad indicada en el último año previo a la encuesta.

Los esposos destacan mayor participación en acciones relacionadas con plantar árboles en la finca, mencionando algunas variedades de árboles, tales como cedro, caoba, madero negro, nogal, y guaba, los cuales se incorporan como sistemas agroforestales. También mencionaron la reforestación de las orillas de los ríos, su participación en brigadas contra incendios forestales y permitir la regeneración natural del suelo.

Las respuestas de las esposas son un poco sorprendentes en comparación con los resultados de la Tabla 12, mostrando muy poca participación en el año anterior a la encuesta (ver Tabla 14). También muestran un patrón diferente con respecto a los grupos de pobreza: entre los pobres, las mujeres participan en más actividades, y las no pobres han participado menos que todas, salvo en los viveros. Aunque las diferencias en las otras tres actividades entre no pobres y muy pobres son muy pequeñas, la diferencia en el patrón entre hombres y mujeres es llamativa. Los resultados pueden sugerir un sistema de valores que ve algunas actividades como "por debajo del estatus" de las mujeres no pobres, tema que merece más investigación.

Las esposas que participan ponen mayor énfasis en plantar árboles en la propia finca, lo cual coincide con la opinión del $98,4 \%$ de las mujeres; que opina que los bosques necesitan reforestación. Las actividades que las mujeres han trabajado de otra manera para mejorar la condición del bosque incluyen el cuidado de la fauna, la concientización sobre la necesidad de cuidar el medio ambiente, hacer rondas y construir cercas vivas.

Tabla 14. Acciones que realizan las esposas por tipo de hogar en condición de pobreza

\begin{tabular}{lrrrrrr}
\hline Actividades de las esposas que participan & \multicolumn{5}{c}{ Condición de pobreza del hogar* } \\
\cline { 2 - 6 } & & No opinó & Muy pobre & Pobre & No pobre \\
\hline Establecimiento y manejo de un vivero & $\mathrm{N}$ & 3 & 2 & 61 & 24 \\
\cline { 2 - 6 } & $\%$ & 9,7 & 2,4 & 7,5 & 9,1 \\
\hline Ha plantado árboles en su finca & $\mathrm{N}$ & 5 & 8 & 104 & 18 \\
\hline Ha plantado árboles en zona forestal comunitaria & $\%$ & 16,1 & 9,6 & 12,8 & 6,8 \\
\hline Ha mejorado la condición de los bosques en alguna u & $\mathrm{N}$ & 2 & 2 & 31 & 4 \\
\hline & & $\%$ & 6,5 & 2,4 & 3,8 & 1,5 \\
\hline
\end{tabular}

Fuente: Encuesta a hogares con acceso a bosques en Nueva Segovia, Matagalpa, Jinotega y Río San Juan *Este porcentaje se refiere a las personasen que se consideraron en ese grupo de pobreza y que participaron en la actividad en el último año, es decir, previo a la encuesta. 


\subsubsection{Participación y organización relacionada con los bosques}

La encuesta buscaba conocer la percepción de las personas respecto a la participación de mujeres en las decisiones sobre los árboles o los bosques considerando varios espacios, desde el hogar hasta las reuniones con otras entidades fuera del gobierno local (ver Tabla 15). Es muy notable el decrecimiento de la participación de las mujeres de la comunidad desde un lugar más privado (78\% en el hogar) a los espacios más públicos (grupos comunales, aproximadamente $29 \%$; reuniones con el gobierno local, 24\%; y reuniones con entidades externas, como ONG, 17\%), tanto en la percepción de los hombres como de las mujeres.

Las mujeres de la encuesta en los hogares con bosque privado perciben la participación femenina en su comunidad en porcentajes similares a los percibidos por los varones en tres de los cuatro lugares donde participan, aunque el porcentaje de su percepción de participación es ligeramente mayor como miembro del grupo comunal (Ver Tabla 15). Aunque el patrón es similar, los resultados son muy diferentes en la encuesta indígena de la RACCN, en la cual la participación de las mujeres también es menor en espacios más públicos; el $63 \%$ de las mujeres perciben que ellas participan en reuniones con "otras partes", la respuesta con niveles de percepción de participación más baja de todas. Las diferencias entre las respuestas de los hombres y de las mujeres también son mayores, y son las mujeres las que perciben menor participación (ver Tabla 16).

Tabla 15. Percepción sobre la participación de las mujeres en decisiones sobre los árboles o el bosque (no-indígena)

\begin{tabular}{lccc}
\hline \multirow{2}{*}{$\begin{array}{l}\text { Dónde y cómo participan las } \\
\text { mujeres de la comunidad }\end{array}$} & \multicolumn{2}{c}{ Informantes } \\
\cline { 2 - 4 } & & Varones & Mujeres \\
\hline A nivel de hogar & $\mathrm{N}$ & 452 & 473 \\
\cline { 2 - 4 } & $\%$ & 77,5 & 78,2 \\
\hline Como miembro del & $\mathrm{N}$ & 166 & 185 \\
\cline { 2 - 4 } grupo comunal & $\%$ & 28,5 & 30,6 \\
\hline $\begin{array}{l}\text { En reuniones del } \\
\text { gobierno local }\end{array}$ & $\mathrm{N}$ & 141 & 147 \\
\hline $\begin{array}{l}\text { En reuniones con } \\
\text { otras partes: ONG, } \\
\text { investigadores, etc. }\end{array}$ & $\mathrm{N}$ & 24,2 & 24,3 \\
\hline
\end{tabular}

Fuente: Encuesta a hogares con acceso a bosques en Nueva Segovia, Matagalpa, Jinotega y Río San Juan
Tabla 16. Percepción sobre la participación de las mujeres en decisiones sobre los árboles o el bosque (indígena)

\begin{tabular}{lcc}
\hline $\begin{array}{l}\text { Dónde y cómo participan las } \\
\text { mujeres de la comunidad }\end{array}$ & \multicolumn{2}{c}{ Informantes } \\
\cline { 2 - 3 } & $\begin{array}{c}\text { Varones } \\
(\%)\end{array}$ & $\begin{array}{c}\text { Mujeres } \\
(\%)\end{array}$ \\
\hline A nivel de hogar & 88,7 & 80,5 \\
\hline $\begin{array}{l}\text { Como miembro del grupo } \\
\text { comunal }\end{array}$ & 80,9 & 75,5 \\
\hline En reuniones del gobierno local & 78,7 & 73,6 \\
\hline $\begin{array}{l}\text { En reuniones con otras partes: } \\
\text { ONG, investigadores, etc. }\end{array}$ & 76,6 & 62,9 \\
\hline
\end{tabular}

Fuente: Datos de la encuesta de hogares indígenas en la RACCN, Alwang, 2012 (comunicación personal)

Comparando la condición de pobreza de los hogares con bosque privado en los cuatro departamentos, son los hogares pobres, seguidos de los no pobres, quienes participan tanto en el hogar como miembros de un grupo comunitario, y para los pobres y no pobres, el hogar es el espacio donde las mujeres son tomadas en cuenta para las decisiones respecto a los árboles y el bosque. Esa pregunta se hizo a hombres y mujeres dentro de los hogares con bosque privado en los cuatro departamentos (no se hizo en la encuesta de la RACCN) para conocer su opinión respecto a su participación en las decisiones sobre los bosques. La mayoría de las mujeres no se vio a sí misma involucrada en las decisiones tomadas sobre el bosque, particularmente en las reuniones relacionadas con el gobierno local $(69 \%)$ o con otras partes interesadas, como ONG, centros de investigación, etc. (80\%). En estos espacios la participación parece más restringida y donde las mujeres se ven con menos posibilidades de ser incluidas.

\subsubsection{Evaluación sobre la calidad de la participación de mujeres y hombres}

La encuesta indagó también la opinión sobre la calidad de la participación de las mujeres y de los hombres de la comunidad en las decisiones sobre la gestión de los bosques (ver Tablas 17 y 18). La calidad debía valorarse en una escala de insignificante a muy bueno. La pregunta mencionó primero explícitamente a las mujeres, luego a los varones y por último preguntó por la opinión de la persona encuestada para referirse a su propia experiencia. A continuación se presentan los resultados por separado, primero la valoración sobre las mujeres, luego la valoración de la calidad de la participación para los varones y por último la de la propia persona encuestada. 
Tabla 17. Opiniones sobre la calidad de la participación de las mujeres

\begin{tabular}{lrrrr}
\hline $\begin{array}{l}\text { Calidad de la } \\
\text { participación de } \\
\text { las mujeres }\end{array}$ & \multicolumn{3}{c}{ Sexo del encuestado } & Total \\
\cline { 2 - 4 } Insignificante & Varones & Mujeres & \\
\cline { 2 - 4 } & $\mathrm{N}$ & 77 & 83 & 160 \\
\hline Pobre & $\mathrm{N}$ & 13,2 & 13,7 & 13,5 \\
\cline { 2 - 4 } & $\%$ & 38,8 & 41,5 & 40,2 \\
\hline Moderado/ & $\mathrm{N}$ & 178 & 154 & 332 \\
\cline { 2 - 4 } Justo & $\%$ & 30,5 & 25,5 & 27,9 \\
\hline Bueno & $\mathrm{N}$ & 90 & 110 & 200 \\
\cline { 2 - 4 } & $\%$ & 15,4 & 18,2 & 16,8 \\
\hline Muy Bueno & $\mathrm{N}$ & 12 & 7 & 19 \\
\cline { 2 - 4 } & $\%$ & 2,1 & 1,2 & 1,6 \\
\hline Total & $\mathrm{N}$ & 583 & 605 & 1188 \\
\cline { 2 - 4 } & $\%$ & 100 & 100 & 100 \\
\hline
\end{tabular}

Fuente: Encuesta a hogares con acceso a bosques en Nueva Segovia, Matagalpa, Jinotega y Río San Juan

La opinión sobre la calidad de participación de las mujeres es valorada como pobre tanto por varones como por mujeres, pero sobre todo por las mujeres. Los varones valoraron como justa o moderada la participación de las mujeres en contraposición a la opinión de las mujeres, quienes valoraron poco este criterio. No obstante, la opinión sobre buena participación alcanzó un mayor porcentaje al ser evaluada por las mujeres, indicando que menos varones perciben la calidad de la participación de las mujeres. Estos datos son indicativos de diferencias en la manera de percibir o valorar este aspecto. En cambio, las opiniones sobre la calidad de la participación de los varones difieren bastante, como muestran los datos de la Tabla 18.

En la Tabla 18, los porcentajes de respuestas de mujeres y varones son bastante similares al evaluar la calidad de participación de los varones en las decisiones sobre la gestión de bosques. Esa valoración oscila entre pobre, moderada y buena, aunque las mujeres evalúan la participación de los varones mejor que ellos mismos en el rango pobre y moderado. Los varones, por su parte, destacan su buena participación, ya que es el indicador que alcanzó el mayor porcentaje de opiniones entre ellos.
Tabla 18. Opinión sobre la calidad de la participación de los varones

\begin{tabular}{|c|c|c|c|c|}
\hline \multirow{2}{*}{\multicolumn{2}{|c|}{$\begin{array}{l}\text { Calidad de la } \\
\text { participación de } \\
\text { los varones }\end{array}$}} & \multicolumn{2}{|c|}{ Sexo del encuestado } & \multirow{3}{*}{$\begin{array}{r}\text { Total } \\
98 \\
\end{array}$} \\
\hline & & \multirow{2}{*}{$\begin{array}{c}\text { Varones } \\
54 \\
\end{array}$} & \multirow{2}{*}{$\begin{array}{c}\text { Mujeres } \\
44\end{array}$} & \\
\hline Insignificante & $\mathrm{N}$ & & & \\
\hline & $\%$ & 9,3 & 7,3 & 8,2 \\
\hline \multirow[t]{2}{*}{ Pobre } & $\mathrm{N}$ & 161 & 172 & 333 \\
\hline & $\%$ & 27,6 & 28,4 & 28,0 \\
\hline \multirow{2}{*}{$\begin{array}{l}\text { Moderado/ } \\
\text { justo }\end{array}$} & $\mathrm{N}$ & 157 & 187 & 344 \\
\hline & $\%$ & 26,9 & 30,9 & 29,0 \\
\hline \multirow[t]{2}{*}{ Bueno } & $\mathrm{N}$ & 172 & 169 & 341 \\
\hline & $\%$ & 29,5 & 27,9 & 28,7 \\
\hline \multirow[t]{2}{*}{ Muy Bueno } & $\mathrm{N}$ & 38 & 31 & 69 \\
\hline & $\%$ & 6,5 & 5,1 & 5,8 \\
\hline \multirow[t]{2}{*}{ No sabe } & $\mathrm{N}$ & 1 & 2 & 3 \\
\hline & $\%$ & 0,2 & 0,3 & 0,3 \\
\hline \multirow[t]{2}{*}{ Total } & $\mathrm{N}$ & 583 & 605 & 1188 \\
\hline & $\%$ & 100 & 100 & 100 \\
\hline
\end{tabular}

Fuente: Encuesta a hogares con acceso a bosques en Nueva Segovia, Matagalpa, Jinotega y Río San Juan

Estos datos son parecidos a la opinión expresada por los varones cuando se trató de evaluar la calidad de su propia participación. Aquí la principal coincidencia fue que los varones señalaron su participación casi en el mismo nivel, es decir, sin diferencias sustantivas en la escala (el $27 \%$ en pobre y moderada y el $28 \%$ en buena participación), a diferencia de las mujeres, ya que el $33 \%$ dijo que su participación era pobre, el $29 \%$ moderada y el $25 \%$ buena.

También se indagó respecto a la participación en organizaciones locales forestales encontrando que la participación en este tipo de organizaciones es limitada. Solo 65 varones (de 583) y 68 mujeres (de 605), es decir, solo el 11\%, dijo que alguien de su familia participa en una organización local como miembro de la organización y muy poco como directivos. El objetivo principal de esas organizaciones locales forestales es la reforestación, seguido del manejo forestal y, en menor medida, la generación de ingresos. Este resultado coincide con la indagación previa para el muestreo en el que intentamos conocer la cantidad de organizaciones forestales existentes en el país y 
del cual no encontramos registro ${ }^{16}$, lo cual parece ser una característica no solo del país, puesto que en América Latina, Babigumira, et al. (2014, p. S77) encontraron que en el $70,2 \%$ de hogares consultados que usan áreas de bosques como parte de sus medios de vida no estaban vinculados a una organización forestal, porque estas no existen. Esto nos lleva a afirmar que el sector forestal está rezagado en comparación con el sector agrícola, en el cual existe buen número de organizaciones cooperativas. De hecho, es el tipo de organización en el sector agrícola que se ha promovido desde el Estado $^{17}$, las organizaciones no gubernamentales y las agencias de cooperación ${ }^{18}$, y un aspecto del cual no se ha beneficiado el sector forestal del país.

\subsection{Resumen}

El bosque tiene importancia para los hogares rurales tanto para quienes tienen tierras privadas como para aquellos con tierras en propiedad comunitaria. El nivel de importancia del bosque varía según la disponibilidad de área y la condición de pobreza en la que se percibe a los miembros del hogar. Para un hogar pobre con parcelas de bosque privado, la agricultura es mucho más relevante para la generación de ingresos que para uno no pobre. La producción forestal es una actividad de relevancia para los hogares pobres y no pobres, pero no lo es para los más pobres. La mayoría de los hogares extraen productos del bosque para satisfacer necesidades del hogar o de la unidad de producción.

16 Organización de dueños de bosques solo existe en Nueva Segovia, en el norte del país, donde la mayoría de los bosques son coníferos.

17 El Gobierno de Unidad y Reconciliación Nacional (GRUN) ha estimulado desde el año 2007 que asumió el gobierno, la organización de cooperativas agrícolas a través de los Bonos Productivos Alimentarios que se han implementado a través de distintas fuentes de apoyo entre ellos el Programa Bonos Productivos AgroAlimentarios con apoyo financiero del BID, fondos de la cooperación de Taiwán y bonos del tesoro nacional.

18 Por ejemplo, los programas de modernización del sector ganadero apoyado con fondos de la Cooperación de Suecia (entre ellos PRODEGA) estimularon la organización de cooperativas de productores de leche condicionando el acceso a recursos financiero al ser cooperativas. Lo mismo realizaron otros programas como FondeAgro en la ganadería, la caficultura y la producción de cacao.
Los hogares se caracterizan por tener áreas pequeñas, la tenencia es privada y los recursos del bosque están en función de las necesidades de la familia, particularmente el agua y la leña. Una diferencia importante ocurre en las comunidades indígenas en cuanto a la propiedad comunitaria de los bosques en comparación al resto del país, que son privadas, pero al mismo tiempo comparten con los hogares con bosques privados una orientación de uso principal de los recursos para los hogares, aunque tienden a extraer también con fines de generación de ingresos.

Existe una relación entre la tenencia de la tierra y las costumbres sobre el traspaso de derechos. Los hombres heredan más el derecho a la tierra que las mujeres, lo que confirma que las prácticas de transferencia de derechos de propiedad por medio de la herencia están influenciadas por los roles sociales de género.

Los resultados también muestran que se reconoce mayor participación de los varones que de las mujeres en la extracción de los recursos del bosque y en la plantación de árboles o manejo de viveros a nivel de sus propiedades. No obstante, hay un porcentaje de hogares donde la participación de ambos (hombres y mujeres) aparece como tarea compartida, en particular en la recolección de frutos silvestres, agua, y leña. Inclusive los hombres reconocieron una mayor participación de mujeres que ellas mismas en la caza de animales silvestres.

Hubo consenso entre hombres y mujeres en que se vislumbra el problema del agotamiento de los recursos, aunque esta percepción es mayor en comunidades no indígenas. El agua y la leña, dos recursos esenciales para la vida en zonas rurales, se perciben como menos abundantes en comparación con las cantidades disponibles diez años atrás.

Mujeres y hombres se reconocen como los principales responsables de asegurar la condición de los bosques, se ven a sí mismos en un rol de creación de reglas para el acceso a los bosques; $y$ en segunda instancia, ven a entidades como la Alcaldía y el gobierno nacional tanto en comunidades indígenas como en el resto del país. Adicionalmente, las actividades relacionadas con los bosques se asumen con mayor preponderancia a nivel de hogar y menos del espacio comunitario. De hecho, la organización forestal comunitaria es inexistente, de modo que los asuntos de interés 
común terminan siendo afrontados a nivel de hogar, y por tanto afrontados en el accionar cotidiano de las mujeres.

Existe correspondencia entre el nivel de pobreza de los hogares y la importancia de la actividad forestal, sola o en combinación con otras actividades. Los muy pobres tienden más al trabajo asalariado, mientras que los pobres se involucran más en la agricultura. Los no pobres y pobres tienen un rol más activo en la extracción forestal, pero los no pobres en el comercio y las remesas. Estas actividades realizadas por los hombres coinciden con aquellas que contribuyen al manejo forestal, donde los más pobres son menos propensos a involucrarse, excepto en la siembra de árboles en tierras comunales.

En los bosques comunitarios, a diferencia de los bosques privados, los hombres y las mujeres extraen más productos del bosque (material para artesanía, frutas y animales silvestres), actividad central y clave para los hogares. Las mujeres indígenas comparten con las no indígenas el hecho de involucrarse menos que los varones en la extracción, pero tienen un rol en la venta y en el control del dinero por la venta de productos. 


\section{Discusión}

Los resultados de las encuestas y el análisis comparativo entre hogares con bosques privados y hogares con bosques comunitarios nos permiten reflexiones sobre varios aspectos centrales. El primero es la participación diferenciada por género en el manejo forestal y la toma de decisiones. Las siguientes secciones incluyen la discusión para entender el significado del trabajo conjunto o la toma de decisiones entre hombres y mujeres, lo cual se relaciona con el siguiente punto en el que afirmamos que la coincidencia de opiniones no implica equidad y que, por tanto, no podemos asumir una sola relación de género en el manejo de los bosques. La próxima sección corresponde a la relación entre tipos de bosques y las diferencias culturales. La siguiente es sobre el aprovechamiento forestal diferenciado, incluyendo la percepción sobre el agotamiento de los recursos. La discusión termina planteando la necesidad de asumir una nueva mirada y valores sobre los bosques como una oportunidad para gestionar la inclusión de una perspectiva de género en la que se puedan beneficiar las mujeres.

\section{Participación diferenciada por género}

Hay formas diferenciadas de participar y de percibir la participación de mujeres y varones en actividades relacionadas con el aprovechamiento y manejo de los bosques. Esto puede estar directamente asociado a las normas de género interiorizadas en las que se espera que el trabajo fuera del hogar sea una responsabilidad de los hombres. El hecho que más hombres que mujeres tengan participación en actividades de extracción, manejo y toma de decisiones sobre los productos del bosque, tanto en hogares con bosques privados como en los hogares de las comunidades indígenas, no es casualidad. Este resultado confirma lo que ya otros estudios han indicado, que hay diferencias de género en el uso de productos del bosque. Por ejemplo, las mujeres se concentran en el uso de productos no maderables usados como materiales para artesanías (Neumann y Hirsch, 2000), como han mostrado los datos de las comunidades indígenas, o que los varones se orientan a la extracción de productos forestales de mayor valor agregado y con fines exportables, mientras las mujeres lo hacen con productos de menor valor y para la economía local, muchas veces sin ceñirse a los parámetros de la economía formal (Awono, et al., 2002; Shackleton, et al., 2011). Recientemente se discute respecto a relativizar roles y diferencias de género, puesto que se ha encontrado que en unos países o regiones la situación respecto a qué hacen hombres y qué hacen mujeres cambia (Manfre y Rubin, 2013), algo mostrado aquí entre las comunidades indígenas y no indígenas. Recientes estudios han encontrado que ambos, mujeres y varones, extraen productos tanto para procesar como no procesados y con fines de ingresos como de consumo (Sunderland, et al., 2014).

\section{La incógnita del trabajo de ambos (hombre- mujer) en la extracción y uso del bosque}

Los datos del estudio indican que las mujeres, cuando se involucran en actividades relacionadas con los bosques, lo hacen solas o en conjunto con sus compañeros tanto en hogares con bosques privados como también en hogares de bosques comunitarios. La extracción de leña, frutas silvestres y madera, así como el establecimiento de viveros y siembra de árboles en la finca, suele ser una actividad que varias mujeres dijeron que comparten con los varones y no la realizan sin ellos. Si bien hay mayor involucramiento de ellos en estas actividades, los datos de la encuesta no nos permiten afirmar que ello se deba a que el trabajo relacionado a los bosques sea exclusivamente del ámbito y dominio masculino. 
¿Cómo entender el significado de esta participación de ambos? Aunque no se exploró en la encuesta, podemos seńalar que cuando se menciona que es un trabajo de los dos, es posible que este sea compartido; es decir, que el hombre y la mujer trabajen en colaboración. Es una actividad que no necesariamente implica equidad para las mujeres, puesto que mientras ellas colaboran con ellos, ellos no lo hacen en la misma medida con el trabajo de ellas en el seno del hogar. De hecho, ellos no reconocieron la responsabilidad de las mujeres en la venta de algunos productos, aunque ellas lo mencionaron de forma explícita como también una responsabilidad femenina. Vimos que la opinión sobre la participación de las mujeres fue menor también en el uso y control de los ingresos que se obtienen de la venta de algunos productos cuando se comercializan. Sin embargo, las opiniones de las mujeres se diferenciaron de la opinión de los varones. Mientras varias de ellas afirmaron que las decisiones son compartidas, el porcentaje de varones que respondió de igual manera es inferior, reflejando diferentes maneras de interpretar el trabajo de ellas, y su común subvalorización (Colfer, et al., 2016).

Trabajar en viveros, plantar árboles en finca y en las áreas comunitarias son tareas que dijeron realizar un poco más de la mitad de los hombres en la encuesta. Las mujeres no están totalmente ausentes en estas tareas, aunque su involucramiento mostró un porcentaje menor al de los hombres. No considerar las razones por las cuales ellas podrían estar participando menos sería injusto, puesto que no entran a estas actividades en la misma condición que los varones. Es probable que el bajo porcentaje de las mujeres esté asociado a la sobrecarga de trabajo que ya ellas tienen en el aseguramiento del funcionamiento de los hogares, o a las restricciones de tiempo que enfrentan debido a los cuidados de los miembros del hogar (preparación de alimentos, aseo de la casa y cuidado de hijos pequeños, enfermos y personas de la tercera edad). Por otro lado, se podría deber también a los posibles riesgos a los que se pueden exponer las mujeres al encontrarse solas en el bosque, aunque en estas circunstancias habría que considerar lo que Villarreal (1992) y McNay, (2000) señalan respecto a la capacidad de agencia de las mujeres, ya que aún en situaciones adversas o desfavorables ellas encuentran alguna posibilidad de maniobra a su favor, no son simples victimas y no se quedan en pasividad.
Estas reflexiones nos llevan a plantear que se necesita desmontar el análisis basado solo en individuos para transcender al análisis de la relación individuo-pareja-familia que es donde mayormente las mujeres están ocupadas. Es decir, se debe pasar al análisis de la relación que establecen los varones en estos tres niveles a efectos de entender si aparecen claramente acciones relacionadas con la colaboración, la retribución y el apoyo mutuo desde los varones como individuos hacia la pareja y la familia, más allá de analizarlos de manera aislada.

\section{Opiniones de mujeres y hombres que coinciden no es igual a equidad}

Las opiniones de las mujeres y los varones, si bien en general tendieron a coincidir en la forma de responder a las preguntas, deben considerarse con cautela, es decir, no deberían interpretarse necesariamente como positivas para las mujeres o que no existen diferencias sesgadas por las normas sociales de género. Para explicarlo mejor, tomamos el ejemplo de la respuesta en la que los varones afirmaron estar de acuerdo en apoyar que sus esposas contribuyan en labores de reforestación, y las mujeres dijeron que, para mejorar las condiciones locales de los bosques, estarían dispuestas a contribuir en labores de replantación de árboles y en labores de ronda o patrullaje. Estas opiniones expresan una idea hacia el futuro y pueden estar basadas más en un deseo que en su realidad objetiva inmediata. No obstante, ello no quita el mérito que se reconoce abiertamente que mujeres y hombres coinciden en pensar que el involucramiento en actividades relacionadas con el bosque no es exclusividad de los varones. Sin duda, expresar opiniones de este tipo para hombres y mujeres representa un avance en términos de reconocer que ellas también tienen un rol central dado que su participación está vinculada y se expresa en el hogar y en complementariedad con la pareja.

Sin embargo, si contrastamos estas respuestas con la manera en que se evaluó la calidad de la participación de las mujeres y los varones, los resultados nos permiten hacer otro tipo de interpretación. Las mujeres evaluaron una participación femenina pobre, igual que los varones, aunque en porcentaje menor que 
ellas. En cambio, la calidad de la participación de los varones se evaluó entre pobre, moderada y buena, mostrando que hay diferencias claras que tienden a favorecer más a los varones. Pasar de una pobre participación a una moderada o más aún, a una buena participación implicaría apertura para que las mujeres (también los varones) puedan incrementar su involucramiento en el aprovechamiento de los productos del bosque en condiciones equitativas a ellos y más allá del propósito de uso para el hogar; en otras palabras, abrir el espacio para un mayor involucramiento y liberar parte de la carga doméstica para un aprovechamiento forestal en función de la generación de ingresos que le permita tener acceso a un trabajo por el cual obtiene remuneración. Esta apreciación es también válida para las comunidades indígenas, donde los hombres suelen dejar toda la responsabilidad del cuidado a las mujeres. Adicionalmente, esto podría traer consigo ciertas modificaciones en el marco de la regulación forestal, al menos para flexibilizar los parámetros establecidos para el aprovechamiento forestal de las actividades en que ellas se involucran.

En paralelo, habría que trabajar en la necesidad de nuevos arreglos intrahogar para balancear la carga y las responsabilidades domésticas con los varones del hogar (todas las edades mayores a 12 años y la relación de parentesco), de tal manera que las mujeres puedan contar no solo con el tiempo sino también con las condiciones familiares (carga doméstica distribuida) para que puedan entrar en procesos de capacitación y formación en temas forestales, para formar parte de organizaciones que les permitan, si así lo desean, realizar actividades que suelen ser tipificadas como masculinas, como el liderazgo en los asuntos forestales, el patrullaje para velar por la protección de las áreas, la supervisión de planes de manejo, o las brigadas para hacer frente a incendios, o aquellas que tienen que ver con el manejo de maquinaria si se tratara de hacer aprovechamiento de ciertos tipos de madera procesada.

\section{No hay una sola relación género-bosques en Nicaragua}

Comparar las respuestas de mujeres y varones de las encuestas con los niveles de pobreza y con el tipo de bosque nos permitió explorar otros aspectos relacionados a las relaciones de género a partir de este cruce de variables. Si bien hay un patrón similar en la manera en que respondieron los varones y las mujeres respecto a su participación en las decisiones sobre los asuntos del bosque, hay claras diferencias que nos permiten plantear que no se puede asumir que hay una sola manera de establecer la relación de género respecto al acceso y uso de los recursos del bosque. Para explicar mejor lo anterior, vemos la similitud en el patrón de respuesta; los hombres pobres y no pobres en los hogares con bosques privados coinciden con las opiniones de los varones en las comunidades indígenas, en que son los hombres quienes tienen mayor participación en las decisiones sobre los bosques en algunos espacios (hogar, miembro de grupo comunitario, reunión con el gobierno local, etc.). A la vez, las mujeres, en comparación con los hombres, coinciden en que sus respuestas son de menor porcentaje, lo cual indica que participan menos que ellos.

Sin embargo, aunque este patrón es común para ambos casos (hombre-mujer en bosque privado y comunal), el resultado de la participación de las mujeres indígenas resultó mejor valorado que la participación de las mujeres en los hogares con bosques privados. Aunque las mujeres indígenas tuvieron, respecto a los varones de sus mismas comunidades, menor participación en espacios públicos, su baja participación es muy alta comparada con la de las mujeres de los hogares en bosques privados. Lo anterior significa que las diferencias de género no solo están relacionadas con la manera en que el binomio hombre-mujer evalúa su relación, sino también al relacionar la posición de las mujeres según el grupo étnico y el tipo de bosque, como otros estudios han indicado al usar el análisis de la intersección entre categorías (Ridgway y Smith, 1999, Yuval-Davis, 2006 y Wharton, 2005).

\section{Otra mirada y valores sobre el bosque: nuevos espacios de gestión e inclusión para la mujer}

Percibimos una necesidad de ampliar la visión sobre el aprovechamiento y manejo de los recursos del bosque como nuevos espacios de gestión, donde se beneficiarían no solo las mujeres, sino también los varones; nuevos espacios también significa nuevos valores. Existen otros tipos de aprovechamiento del bosque que han empezado a generar mercados emergentes como los mercados de carbono, el ecoturismo, la producción de medicamentos o el tratamiento no convencional de 
problemas de salud, la generación de agua limpia para el consumo humano o con fines de generación de energía renovable que aún son incipientes en el país. Todas estas opciones podrían estar más en sintonía con esa característica desarrollada para los servicios hacia los demás (Lagarde, 2005) en el que las mujeres podrían encontrar menos resistencia $\mathrm{u}$ obstáculos para ser incluidas. Esto se puede usar como plataforma para el cambio de la dimensión del género femenino en el sector. Ampliar la visión implica otra mirada del aprovechamiento forestal que recupera sus valores intrínsecos, no solo por los árboles, sino por todo el ecosistema involucrado. Para esto, es necesario reducir el sesgo agrícola, al menos de ese que cambia la vocación del suelo, ese que se enfoca en el monocultivo y la ganadería extensiva depredadora de los bosques (Bermúdez, et al., 2015). Si bien este cambio de paradigma respecto al sector forestal va más allá de abrir espacios para las mujeres rurales (campesinas o indígenas), así como para la pequeña propiedad con áreas de bosque, en realidad, demanda un cambio estructural en la forma de pensamiento, los enfoques y las estrategias en los que las mujeres en hogares con bosques privados y las mujeres indígenas de bosques comunitarios estén expresamente incluidas. Para ello, es preciso reconocer que hay diferencias en la visión y de poder entre los hogares que son dueños de pequeñas áreas de bosques, los hogares que son dueños de los bosques comunitarios, los empresarios forestales (medianos y grandes) con un rol importante en la cadena de productos forestales, las entidades del Estado vinculadas al sector forestal y las agencias de cooperación.

\section{Tipos de bosques y diferencias culturales}

De igual manera, se aprecian diferencias en la importancia que representan los bosques para mujeres y hombres en hogares con bosques privados y hogares con bosques comunitarios. Para las personas indígenas, los bosques son más importantes para la vida en el hogar y por la variedad de productos que se pueden obtener de ellos; para personas campesinas, los bosques son importantes por las costumbres y tradiciones que unos y otros manejan respecto a las áreas de bosque y la actividad agrícola. Los hombres de los hogares con bosques privados están más orientados a las actividades agrícolas en sus medios de vida, es decir dependen más de la venta de granos que cultivan que de los recursos que extraen del bosque, mientras que los hombres en los hogares con bosques comunitarios combinan la agroforestería en un sistema de trabajo que permite cultivar para el consumo y la venta, pero también extraer productos del bosque para comercializar cuando lo requieren. De igual manera el sistema de trabajo agrícola permite recuperar un área boscosa con mayor rapidez al dejar descansar la tierra y mover sus cultivos a nuevos sitios, algo que los campesinos no pueden hacer al tener más restricciones de tierra.

El bosque privado y el bosque comunitario son las dos distinciones importantes en el estudio de donde surgen diferencias importantes, incluyendo las culturales. Estas diferencias permean de una u otra manera la forma en que mujeres y hombres se involucran en actividades de manejo forestal. Los bosques comunitarios, siendo más extensos que los bosques privados, proveen más recursos a los hogares que los segundos (animales y frutas silvestres, miel, material para artesanía) y se manejan de manera comunitaria bajo el régimen de autonomía regional en el marco de la ley 445.

\section{Aprovechamiento forestal diferenciado $y$ percepción de agotamiento de los recursos}

Aunque el aprovechamiento forestal con fines comerciales por parte de los hogares es limitado tanto en los bosques privados como en los comunales, presenta diferencias dependiendo de la disponibilidad del área, pero sobre todo del tipo de propiedad y de la cercanía o lejanía del mercado. En el bosque comunitario se puede extraer madera para comercializar, pero en el bosque privado, la extracción es más limitada. Dos posibles escenarios podrían influir en este resultado de poco aprovechamiento para la comercialización. Por un lado, es altamente probable que esté influido por el marco normativo existente, dado que hay una serie de trámites y exigencias que deben ser llenadas para obtener permisos para la extracción de productos, con el riesgo de que estos sean denegados.

Otra posible influencia, especialmente para los hogares con bosques privados, son las denuncias que suelen hacer los miembros de la comunidad al enterarse que hay personas tumbando árboles dentro de su propiedad. Esta práctica ha ido aumentando a medida que las preocupaciones ambientales se incrementan y se enfrentan los efectos del cambio climático. De hecho, la 
encuesta señala que hay mayor percepción de escasez de productos del bosque en hogares con bosques privados que en aquellos con bosques comunitarios, un hecho que puede estar influido no solo por la cantidad de área disponible, sino también por la presión de la población sobre los recursos. Aunque la encuesta no lo abordó, es probable que la percepción de escasez de productos esté influyendo o influya a futuro en un tensionamiento en los roles de género. Esto estaría afectando de manera desproporcionada a las mujeres, ya que su responsabilidad exclusiva en la preparación de alimentos, la limpieza del hogar, el lavado de la ropa y la higiene de los niños está relacionada con el acceso al agua de fuentes superficiales.

En este escenario de poco aprovechamiento forestal, es probable que también influya el escaso mercado de otros productos del bosque e incluso la mala imagen del mercado ilegal de estos productos. También es posible que la madera que queda en los remanentes de bosques no tenga un alto el valor económico, en comparación con valor que adquieren ciertos tipos de madera. Esto, como se mencionó antes, puede derivarse de que el trabajo en el bosque para nutrir la familia o asegurar la vida en el hogar no pasa por la relación mercantilizada sobre la naturaleza, los productos del bosque y sobre el trabajo de llevarlos y consumirlos en el hogar.

Un segundo escenario, aunque menos probable, podría ser que las familias, en realidad, no tengan interés en la comercialización de todos los recursos del bosque que poseen o a los que pueden tener acceso, dado que la actividad agrícola podría tener más relevancia que la forestal; probablemente, porque son pequeñas manchas boscosas cuyo fin es proveer leña y proteger las fuentes de agua. A ello también se podría asociar la falta de recursos para invertir en equipos o herramientas adecuadas para aprovechar algunos recursos del bosque, así como el escaso conocimiento sobre la biodiversidad existente y el potencial del valor de mercado de algunos productos. 


\section{Conclusiones}

Apelamos a la necesidad de abrir una discusión respecto al papel del Estado, los hogares con bosques privados y los hogares con bosques comunitarios frente a la gestión y al manejo de los bosques. En las encuestas, las mujeres y los hombres encuentran que esta es una responsabilidad compartida con las autoridades, como lo son las decisiones para el manejo y uso de productos del bosque entre hombre y mujeres. No obstante, necesitamos entender más acerca del "trabajo conjunto" o la "responsabilidad de ambos" en el manejo y en las decisiones sobre los productos y usos del bosque, y lo que esto significa en términos de diferenciación y de relaciones de género. Profundizar en este tipo de análisis es clave por su potencial para encontrar nuevas percepciones dentro de los problemas relacionados con el trabajo no compartido del hogar.

Remarcamos que estimular mayor participación de las mujeres y mayor colaboración hombremujer en el trabajo conjunto no solo en el bosque, sino también en las labores del cuidado del hogar, podría ser una ruta para disminuir las brechas de inequidad de género en la medida en que los beneficios sean parejos para todos los integrantes del hogar.

Por último, también necesitamos entender más acerca del género, la clase y la cultura y su interacción con las decisiones que se toman para los usos del bosque. Tan importante es avanzar en esta lectura de la interacción humana con los bosques, como también del papel del bosque como entidad que se desdobla por la interacción humana en dos dimensiones, lo privado y lo público. Reconocemos que si bien hay nuevos valores de creciente importancia de los bosques en la mitigación del cambio climático, las decisiones sobre el futuro de ellos nos atañen a todos y todas. Por lo tanto, el diálogo y la concertación entre los hogares con o sin bosques es crucial. En particular, los hogares con bosques privados de pequeña y gran escala, las comunidades indígenas con bosques comunitarios, el gobierno y el sector de la pequeña y mediana empresa forestal o agroforestal necesitan mayor articulación por la necesidad de reducir no solo el impacto del cambio climático, sino también las brechas de iniquidad de género y hacer explícita la incorporación de las preocupaciones, percepciones y planteamientos de las mujeres.

Aunque todos estos hallazgos requieren más investigación, nos permiten contribuir al análisis de Sunderland, et al. (2014) respecto a las diferencias de género en el manejo forestal en varias regiones del mundo (América Latina, África y Asia). Este estudio sugiere que un análisis más profundo dentro de cada región puede también encontrar diferencias grandes entre las comunidades y culturas indígenas de bosque tropical. Estos temas deben ser incluidos en futuros trabajos de investigación, y para ello, el uso de métodos cualitativos permitiría entender mejor o profundizar en las experiencias y perspectivas de las mujeres y los varones en el manejo de bosques según otras variables como la edad, la escolaridad, si forman parte o no de organizaciones de dueños de bosques, y si tienen mejor o peor acceso al mercado, entre otras. 


\section{Referencias}

Agarwal, B. (1990). El Debate sobre género y medio ambiente en la India. Ponencia presentada en la conferencia sobre Cuestiones del Medio Ambiente y El Desarrollo Emergente. Instituto Internacional de Investigación sobre Economía del Desarrollo, Helsinki, Finlandia.

Alcorn, J. (2014). Lessons Learned from Community Forestry in Latin America and Their Relevance for REDD+. USAID-supported Forest Carbon, Markets and Communities (FCMC) Program. USAID, Washington D. C., Estados Unidos.

Asamblea Nacional (2003). Reglamento de la Ley No. 462, ley de conservación, fomento y desarrollo sostenible del sector forestal. Decreto No. 73-2003. Managua, Nicaragua. Obtenido de www.legislacion.asamblea.gob.ni

Asamblea Nacional (2006). Ley de veda para el corte, aprovechamiento y comercialización del recurso forestal, ley No. 585 aprobada el 7 de junio del 2006. Managua, Nicaragua.

Awono, A., Ndoye, O., Schreckenberg, K.,

Tabuna, H., Isseri, F. y Temple, L. (2002).

Production and marketing of safou (Dacryodes edulis) in Cameroon and internationally: market development issues. Forests, Trees and Livelihoods, 12(1-2), 125-147.

Babigumira, R., Angelsen, A., Buis, M., Bauch, S. y Sunderland, T. (2014). Forest clearing in rural livelihoods: Household-level globalcomparative evidence. World Development, 64, S67-S79.

BCN (2014). Informe Anual 2014 consultado 10 de abril 2014. Obtenido de www.ben.gob. ni: http://www.bcn.gob.ni/publicaciones/ periodicidad/anual/informe_anual/informe_ anual_2014.pdf

Bermúdez, M., Flores, S., Romero, M., Bastiaensen, J., Merlet, P., Huybrechs, F., Van Hecken, G y Ramírez, J. (2015). ¿Es posible financiar la ganadería en la frontera agrícola de Nicaragua de manera sostenible? Nitlapan, IOB, ADA, Managua.
CIFOR (2013). Bosque y género: lo que deberian de saber los formuladores de politicas. Factsheet. (CIFOR, Ed.) Recuperado el Julio de 2015, de www.cifor.org: http://www.cifor. org/publications/pdf_files/factsheet/4178factsheet.pdf

Colfer, C.J.P., Elias, M. y Basnett, B.S. (2016). A gender box analysis of forest management and conservation. En C.J.P. Colfer, B.S. Basnett y M. Elias, Gender and forests: Climate change, tenure, value chains and emerging issues. Earthscan, Londres, Reino Unido.

Contreras, A. (2011). Pueblos, gobernanza y bosques, los obstáculos a la reforma de la gobernanza forestal en América Latina. En A. Larson y E. Petkova, Gobernanza forestal y REDD + Desafios para las políticas y mercados en America Latina. CIFOR, Bogor, Indonesia.

Estado de la Región (2011). Panorama Ambiental, capítulo 5. Informe del Estado de la Region.

FAO (2009). Cerrar la brecha: el programa de la FAO para la igualdad de género en la agricultura y el desarrollo rural. FAO.

FAO. (2013). Los bosques, la seguridad alimentaria y el género: vínculos, disparidades y prioridades para la acción. Documento de antecedentes para la Conferencia Internacional sobre los bosques y la seguridad alimentaria y nutricional, 13-15 mayo. FAO, Roma, Italia.

Fraser, N. (2007). Feminist Politics in the Age of Recognition: A Two-Dimensional Approach to Gender Justice. Studies in Social Justice, Volume 1, Number 1, Winter, 23-35.

GFA Consulting Group. (2008). Informe de Evaluación de la integración de Equidad de Género y descripción de las estrategias para promover su participación. Recuperado el 23 de Marzo de 2015, de http://www.cuentadelmilenio.org.ni/ cedoc/11genero/15\%20planificacion

Guevara, M. (2004). Tendencias y perspectivas del sector forestal en América Latina al año 2020. Informa Nacional Nicaragua. FAO. 
INAFOR (2009). Boletín Estadistico del Sector Forestal 2000-2009. INAFOR/MAGFOR, Managua, Nicaragua.

INAFOR (2009). Resultados del Inventario Nacional Forestal: Nicaragua 2007-2008 Primera edición, $232 p$. Recuperado el 11 de abril de 2015, de www.inafor.gob.ni: www. inafor.gob.ni/Inventario/Pdfs/Informe $\% 20$ Final\%20.pdf

Lagarde, M. (2005). Los cautiverios de las mujeres: madresposas, monjas, putas, presas y locas. Universidad Nacional Autónoma de México, México.

Larson, A. (2006). Los grupos marginados, la descentralización y el sector forestal en Nicaragua. Primera Edición, CIFOR-CIID. Plural Editores, Bolivia.

MAGFOR (2008). Programa Forestal Nacional del Poder Ciudadano. Recuperado el 2015 de abril de 2014, de www.magfor.gob.ni: www. magfor.gob.ni/prorural/programasnacionales/ planforestal.pdf

Mai, Y., Mwangi, E. y Wan, M. (2011). Gender analysis in forestry research: Looking back and thinking ahead. International Forestry Review 13(2), 245-258.

Mairena, E., Lorío, G., Hernández, X., Wilson, C., Muller, P. y Larson, A. (2012). Gender and forests in Nicaragua's indigenous territories: From national policy to local practice (95 No. Working Paper). CIFOR, Bogor, Indonesia.

Manfre, C. y Rubin, D. (2013). Integrating gender into forestry research, a guide for CIFOR scientists and programme administrators. CIFOR, Bogor, Indonesia.

McNay, L. (2000). Gender and Agency: Reconfiguring the subject in feminist and social theory. Polite Press.

Neumann, R. y Hirsch, E. (2000). Commercialisation of non-timber forest products, review and analysis of research. CIFOR, Bogor, Indonesia.

Ortega, M. (2014). Linea base de uso y destino de la madera aserrada en Nicaragua con referencia al ciclo 2012-2013. GIZ, Managua, Nicaragua.
Ridgway, C. y Smith, L. (1999). The gender system and interaction. Annual Review of Sociology 25, 191-216.

Ruiz, D. y López, I. (2003). Equidad de género, medio ambiente y políticas públicas: el caso de México y la Secretaría de Medio Ambiente y Recursos Naturales. Revista de Estudios de Género, La Ventana, No. 17, 43-77. Universidad de Guadalajara, México.

Schmink, M. y García, M. A. (2015). Bajo el dosel: Género y bosques en la Amazonía. Documentos Ocasionales 125. CIFOR, Bogor, Indonesia.

Shackleton, S., Paumgarten, F., Kassa, H., Husselman, M. y Zida, M. (2011). Opportunities for enhancing poor women's socioeconomic empowerment in the value chains of three African non-timber forest products. International Forestry Review, 13(2), 136-151.

Sunderland, T., Achdiawan, R., Angelsen, A., Babigumira, R., Ickowitz, A., Paumgarten, F., . .. Shively, G. (2014). Challenging percpections about men, women and forest product use: A global comparative study. World Development, No. 64., 56-66.

Villarreal, M. (1992). The poverty of practice Power, gender and intervention from an actororiented perspective. En N. Long y A. Long, Battlefields of Knowledge: the interlocking of theory and practice in social research and development. (págs. 247-267). Routledge, Londres, Reino Unido.

Wharton, A. (2005). The Sociology of Gender, an introduction to Theory and Research. Blackwell Publishing.

Wunder, S., Angelsen, A. y Belcher, B. (2014). Forests, livelihoods, and conservation: broadening the empirical base. World Development, 64, S1-S11.

Wunder, S., Borner, J., Shively, G. y Wyman, M. (2014). Safety nets, gap filling and forests: A global-comparative perspective. World Development, 64, S29-S42.

Yuval-Davis, N. (2006). Intersectionality and Feminist Politics.13. European Journal of Women's Studies, 193-209. 


\section{Anexos}

\section{Anexo 1. Superficie de bosque por comunidad, municipio y departamento}

\begin{tabular}{|c|c|c|c|}
\hline Departamento & Municipio & Comunidad & Superficie de Bosque Total (mz) \\
\hline \multirow[t]{11}{*}{ Nueva Segovia } & \multirow[t]{3}{*}{ Jalapa } & El Corozo & 1101,24 \\
\hline & & Carbon & 830,97 \\
\hline & & El Porvenir & 363,73 \\
\hline & \multirow[t]{3}{*}{ El Jícaro } & Villa Nueva & 1369,49 \\
\hline & & El Arado Grande & 310,00 \\
\hline & & El Calvario & 109,00 \\
\hline & \multirow[t]{2}{*}{ Mozonte } & El Arado & 643,50 \\
\hline & & Villa Fontana & 543,00 \\
\hline & \multirow[t]{3}{*}{ Dipilto } & Loma Fría & 423,79 \\
\hline & & Dipilto Nuevo & 145,87 \\
\hline & & Las Nubes & 68,49 \\
\hline \multirow[t]{4}{*}{ Jinotega } & \multirow[t]{4}{*}{ El Cuá } & Peñas Blancas \#1 y \#2 & 1389,55 \\
\hline & & El Cielo & 340,00 \\
\hline & & La Chata & 38,60 \\
\hline & & San Miguel & 274,14 \\
\hline \multirow[t]{7}{*}{ Matagalpa } & \multirow[t]{4}{*}{ Río Blanco } & El Martillo & 1523,90 \\
\hline & & Germán Pomares & 369,00 \\
\hline & & Paláan & 222,30 \\
\hline & & Manceras & 195,75 \\
\hline & \multirow[t]{3}{*}{ El Tuma - La Dalia } & Peñas Blancas & 1897,71 \\
\hline & & Wasaka (y Wasakita) & 738,34 \\
\hline & & El Carmen & 234,25 \\
\hline \multirow[t]{6}{*}{ Río San Juan } & \multirow[t]{3}{*}{ San Miguelito } & Los Potreros & 1948,50 \\
\hline & & Los Pantanos & 1340,99 \\
\hline & & Mancha De Coyol & 581,00 \\
\hline & \multirow[t]{3}{*}{ San Carlos } & Pueblo Nuevo \#1 Y \#2 & 1164,73 \\
\hline & & Melchora (y Melchorita) & 1055,55 \\
\hline & & Esperanza \#1 y \#2 & 355,35 \\
\hline
\end{tabular}

Fuente: INIDE (2011) Cuarto Censo Nacional Agropecuario, Base de datos del uso del suelo en bosques totales. Managu. 
Anexo 2. Listado de encuestas realizadas por sexo en municipios y comunidades

\begin{tabular}{|c|c|c|c|c|}
\hline \multirow[t]{2}{*}{ Municipios } & \multirow[t]{2}{*}{ Comunidades } & \multicolumn{2}{|c|}{ Sexo del encuestado } & \multirow[t]{2}{*}{ Total } \\
\hline & & Varones & Mujeres & \\
\hline \multirow[t]{4}{*}{ Jalapa } & El Corozo & 36 & 36 & 72 \\
\hline & Carbón & 31 & 33 & 64 \\
\hline & Las Delicias & 2 & 2 & 4 \\
\hline & Subtotal & 69 & 71 & 140 \\
\hline \multirow[t]{2}{*}{ El Jícaro } & Villanueva & 31 & 33 & 64 \\
\hline & Subtotal & 31 & 33 & 64 \\
\hline \multirow[t]{3}{*}{ Mozonte } & El Arado & 34 & 36 & 70 \\
\hline & Quisuli & 35 & 35 & 70 \\
\hline & Subtotal & 69 & 71 & 140 \\
\hline \multirow[t]{5}{*}{ Dipilto } & Loma Fría & 9 & 9 & 18 \\
\hline & Dipilto Nuevo & 46 & 48 & 94 \\
\hline & Las Nubes & 12 & 12 & 24 \\
\hline & Dipilto Viejo & 3 & 3 & 6 \\
\hline & Subtotal & 70 & 72 & 142 \\
\hline \multirow[t]{5}{*}{ El Cuá } & Rosa Amelia & 19 & 19 & 38 \\
\hline & Peñas Blancas & 36 & 34 & 70 \\
\hline & La Chata & 15 & 17 & 32 \\
\hline & San Miguel & 35 & 35 & 70 \\
\hline & Subtotal & 105 & 105 & 210 \\
\hline \multirow[t]{3}{*}{ Río Blanco } & Palán & 42 & 42 & 84 \\
\hline & Manceras & 26 & 30 & 56 \\
\hline & Subtotal & 68 & 72 & 140 \\
\hline \multirow[t]{3}{*}{ El Tuma-La Dalia } & Peñas Blancas & 34 & 36 & 70 \\
\hline & Wasaka/Wasakita & 37 & 33 & 70 \\
\hline & Subtotal & 71 & 69 & 140 \\
\hline \multirow[t]{5}{*}{ San Miguelito } & La conquista & 5 & 5 & 10 \\
\hline & Los Potreros & 25 & 27 & 52 \\
\hline & Los Pantanos & 12 & 14 & 26 \\
\hline & Mancha de Coyol & 9 & 9 & 18 \\
\hline & Subtotal & 51 & 55 & 106 \\
\hline \multirow[t]{3}{*}{ San Carlos } & Pueblo Nuevo & 26 & 26 & 52 \\
\hline & Esperanza & 23 & 31 & 54 \\
\hline & Subtotal & 49 & 57 & 106 \\
\hline Total: 9 municipios & 24 comunidades & 583 & 605 & 1188 \\
\hline
\end{tabular}


Anexo 3. Pruebas estadísticas de diferencia significativa entre varones y mujeres sobre la relevancia de la actividad de pesca y remesas

Relevancia de la pesca en los medios de vida familiares

\begin{tabular}{lccc}
\hline Nivel de importancia & Varones & Mujeres & Total \\
\hline Más importante & 1 & 0 & 1 \\
\hline Importante & 23 & 20 & 43 \\
\hline Menos importante & 7 & 2 & 9 \\
\hline No importante & 1 & 7 & 8 \\
\hline Total & 32 & 29 & 61 \\
\hline Pearson chi2 $(3)=8,3598$ & $\operatorname{Pr}=0,039$ & &
\end{tabular}

Relevancia de las remesas en los medios de vida familiares

\begin{tabular}{lccc}
\hline Nivel de importancia & Varones & Mujeres & Total \\
\hline Más importante & 15 & 10 & 25 \\
\hline Importante & 8 & 10 & 18 \\
\hline Menos importante & 2 & 10 & 12 \\
\hline No importante & 10 & 7 & 17 \\
\hline Total & 35 & 37 & 72
\end{tabular}

Pearson chi2(3) $=7,0348 \quad \operatorname{Pr}=0,071$

Anexo 4. Prueba estadística de la significancia de la agricultura de subsistencia por condición del hogar

\begin{tabular}{lccccc}
\hline \multirow{2}{*}{$\begin{array}{l}\text { Nivel de importancia } \\
\text { atribuida }\end{array}$} & \multicolumn{4}{c}{ Condición de pobreza de la familia según su autopercepción } \\
\cline { 2 - 6 } & No opinó & Muy pobre & Pobre & No pobre & Total \\
\hline Más importante & 19 & 27 & 339 & 78 & 459 \\
\hline Importante & 1 & 24 & 205 & 87 & 317 \\
\hline Menos importante & 0 & 0 & 10 & 9 & 19 \\
\hline Total & 20 & 554 & 170 & 795 \\
\hline Pearson chi2 $(6)=33,9423$ & $\operatorname{Pr}=0,000$ & & &
\end{tabular}

\section{Anexo 5. Diferencia significativa de la producción forestal según la condición del hogar}

\begin{tabular}{lccccc}
\hline \multirow{2}{*}{$\begin{array}{l}\text { Nivel de importancia } \\
\text { atribuida }\end{array}$} & \multicolumn{4}{c}{ Condición de pobreza de la familia según su autopercepción } \\
\cline { 2 - 6 } & No opinó & Muy pobre & Pobre & No pobre & Total \\
\hline Más importante & 0 & 1 & 9 & 6 & 16 \\
\hline Importante & 5 & 5 & 65 & 39 & 114 \\
\hline Menos importante & 5 & 5 & 62 & 10 & 82 \\
\hline No importante & 0 & 0 & 4 & 1 & 5 \\
\hline Total & 10 & 11 & 140 & 56 & 217 \\
\hline Pearson chi2 & $(9)=14,7812$ & $\operatorname{Pr}=0,097$ & & & \\
\hline
\end{tabular}


Anexo 6. Diferencia significativa de la actividad asalariado temporal según la condición del hogar

\begin{tabular}{lccccc}
\hline \multirow{2}{*}{$\begin{array}{l}\text { Nivel de importancia } \\
\text { atribuida }\end{array}$} & \multicolumn{4}{c}{ Condición de pobreza de la familia según su autopercepción } \\
\cline { 2 - 6 } & No opinó & Muy pobre & Pobre & No pobre & Total \\
\hline Más importante & 0 & 1 & 9 & 6 & 16 \\
\hline Importante & 5 & 5 & 65 & 39 & 114 \\
\hline Menos importante & 5 & 5 & 62 & 10 & 82 \\
\hline No importante & 0 & 0 & 4 & 1 & 5 \\
\hline Total & 10 & 11 & 140 & 56 & 217 \\
\hline Pearson chi2 $(6)=14,7812$ & $\operatorname{Pr}=0,097$ & & & \\
\hline
\end{tabular}

\section{Anexo 7. Diferencia significativa de la actividad del comercio según la condición del hogar}

\begin{tabular}{lccccc}
\hline \multirow{2}{*}{$\begin{array}{l}\text { Nivel de importancia } \\
\text { atribuida }\end{array}$} & \multicolumn{4}{c}{ Condición de pobreza de la familia según su autopercepción } \\
\cline { 2 - 6 } Más importante & No opinó & Muy pobre & Pobre & No pobre & Total \\
\hline Importante & 3 & 5 & 49 & 44 & 101 \\
\hline Menos importante & 0 & 1 & 30 & 5 & 36 \\
\hline No importante & 0 & 0 & 7 & 2 & 9 \\
\hline Total & 0 & 0 & 6 & 1 & 7 \\
\hline Pearson chi2 $(6)=17,4527$ & 3 & 6 & 92 & 52 & 153 \\
\hline
\end{tabular}

\section{Anexo 8. Diferencia significativa de las remesas según la condición del hogar}

\begin{tabular}{lccccc}
\hline \multirow{2}{*}{$\begin{array}{l}\text { Nivel de importancia } \\
\text { atribuida }\end{array}$} & \multicolumn{4}{c}{ Condición de pobreza de la familia según su autopercepción } \\
\cline { 2 - 6 } & No opinó & Muy pobre & Pobre & No pobre & Total \\
\hline Más importante & 1 & 3 & 11 & 10 & 25 \\
\hline Importante & 1 & 2 & 7 & 8 & 18 \\
\hline Menos importante & 0 & 0 & 11 & 1 & 12 \\
\hline No importante & 0 & 0 & 14 & 3 & 17 \\
\hline Total & 2 & 5 & 43 & 22 & 72 \\
\hline Pearson chi2 (9) $=15,4077$ & $\mathrm{Pr}=0,080$ & & &
\end{tabular}



Los Documentos ocasionales de CIFOR contienen resultados de investigación relevantes para el manejo forestal. Su contenido es revisado por pares interna y externamente.

Existen generalizaciones sobre las mujeres y los bosques que han sido cuestionadas por estudios recientes que muestran diferencias importantes entre África, Asia y América Latina. En Nicaragua, las políticas, los proyectos y la gestión forestal suelen dejar fuera al conocimiento, las preocupaciones y los intereses de las mujeres. Esta investigación presenta los resultados de dos encuestas con el propósito de entender las percepciones, la toma de decisiones y la participación de mujeres y hombres en actividades relacionadas con el uso de los bosques. Las encuestas, una en cuatro departamentos en el oeste y región central del país (Nueva Segovia, Matagalpa, Jinotega y Río San Juan) y la otra con comunidades indígenas en la Región Autónoma de la Costa Caribe Norte (RACCN), también señalan diferencias importantes dentro de un mismo país, por región y por cultura, subrayando la necesidad de estudios de mayor profundidad para mejorar la gestión forestal de manera inclusiva.

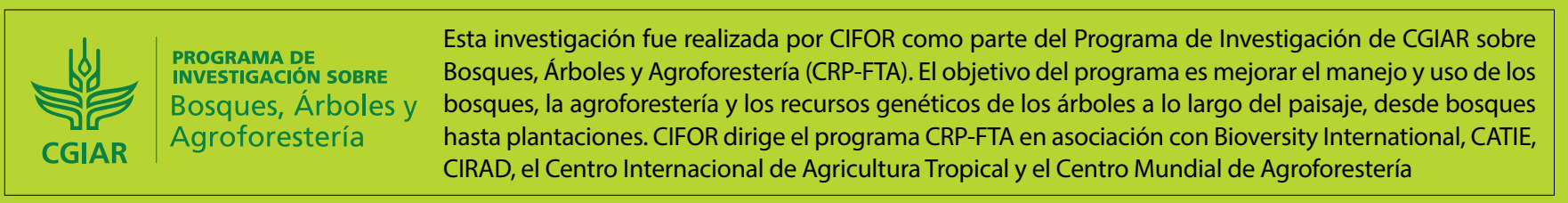

cifor.org

blog.cifor.org

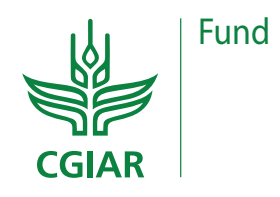

Fund
Centro para la Investigación Forestal Internacional (CIFOR)

CIFOR promueve el bienestar humano, la integridad del medio ambiente y la equidad mediante investigación de avanzada, desarrollando las capacidades de sus socios y dialogando activamente con todos los actores involucrados, para informar sobre las políticas y las prácticas que afectan a los bosques y a las personas. CIFOR es un centro de investigación CGIAR y lidera su Programa de Investigación sobre Bosques, Árboles y Agroforestería (FTA por sus siglas en inglés). Nuestra sede central se encuentra en Bogor, Indonesia, y contamos con oficinas en Nairobi, Kenia; Yaundé, Camerún; y Lima, Perú. 